\title{
Continuous and Transient Vesicle Cycling at a Ribbon Synapse
}

\author{
Ned C. Rouze and Eric A. Schwartz \\ Department of Pharmacological and Physiological Sciences, The University of Chicago, Chicago, Illinois 60637
}

Optical methods were used to study the $\mathrm{Ca}^{2+}$ dependence of vesicle cycling in bipolar cells isolated from goldfish retinas. Uniformly raising the $\mathrm{Ca}^{2+}$ concentration to between 0.8 and $20 \mu \mathrm{M}$ produced a continuous vesicle cycle of balanced exocytosis and endocytosis with a maximum rate equivalent to the turnover of the entire surface membrane of a terminal every 2 min (or $\sim 900$ vesicles $\mathrm{sec}^{-1}$ ). Increasing the $\mathrm{Ca}^{2+}$ concentration above $20 \mu \mathrm{M}$ inhibited continuous vesicle cycling. In contrast, influx of $\mathrm{Ca}^{2+}$ through voltage-gated channels produced a transient burst of exocytosis that increased the surface area of a terminal by a maximum of $12 \%$ (equivalent to the addition of 13,000 vesicles). Endocytosis was delayed until after $\mathrm{Ca}^{2+}$ influx stopped and the average $\mathrm{Ca}^{2+}$ concentration in the terminal declined. Hence, a single terminal has mechanisms for both continuous and transient vesicle cycling.

Key words: exocytosis; endocytosis; vesicle cycling; synaptic vesicle; bipolar cell; retina
$\mathrm{Ca}^{2+}$ influx has long been known to be an effective trigger for regulated exocytosis (Katz and Miledi, 1967). The coupling between $\mathrm{Ca}^{2+}$ and fusion has been studied extensively in neuroendocrine cells. Most studies have demonstrated that $\mathrm{Ca}^{2+}$ concentrations above a few micromolar are sufficient to trigger exocytosis (see, for example, Jankowski et al., 1992). Less is known about vesicle cycling in presynaptic nerve endings, which are usually small and consequently have been experimentally inaccessible. Only recently have the $\mathrm{Ca}^{2+}$ dependence and kinetics of vesicle cycling been studied in large synaptic terminals containing ribbon synapses. A change in membrane capacitance has been used to monitor vesicle fusion in retinal bipolar and photoreceptor cells. Surprisingly, two different views have emerged. Goldfish bipolar cells (Heidelberger et al., 1994; von Gersdorff and Matthews, 1994a) transiently released vesicles when the $\mathrm{Ca}^{2+}$ concentration exceeded $20 \mu \mathrm{M}$. In contrast, salamander rod photoreceptors (Rieke and Schwartz, 1996) sustained a continuous vesicle cycle when the $\mathrm{Ca}^{2+}$ concentration rose above $1 \mu \mathrm{M}$. A similar conclusion was reached after staining goldfish bipolar cells with a fluorescent dye and following the fate of tagged vesicles (Lagnado et al., 1996) (however, see the Appendix). Thus, the experiments paint pictures of synaptic vesicle cycling that differ in two important respects. First, the $\mathrm{Ca}^{2+}$ concentrations required for release differ $>20$-fold. Second, the entire process of release and vesicle resupply is either transient or continuous.

We have now reconciled these divergent views. Vesicle cycling was observed after bipolar cell membranes were stained with FM1-43 or FM4-64. Relatively low $\mathrm{Ca}^{2+}$ concentrations $(0.8-20 \mu \mathrm{M})$ stimulated exocytosis and sustained a continuous vesicle cycle with maximal rates sufficient to replace the entire surface of a terminal every $2 \mathrm{~min}$. Higher concentrations $(>20$ $\mu \mathrm{M})$ inhibited continuous cycling. Large increases in the local concentration near voltage-gated channels produced a transient

\footnotetext{
Received May 14, 1998; revised Aug. 7, 1998; accepted Aug. 13, 1998.

This work was supported by a grant from the National Institutes of Health.

Correspondence should be addressed to Dr. Eric Schwartz, Department of Pharmacological and Physiological Sciences, The University of Chicago, 947 East 58th Street, Chicago, IL 60637.

Copyright (ㄷ) 1998 Society for Neuroscience $\quad 0270-6474 / 98 / 188614-11 \$ 05.00 / 0$
}

burst of exocytosis. A rapid wave of compensatory endocytosis was initiated after $\mathrm{Ca}^{2+}$ influx stopped and the average $\mathrm{Ca}^{2+}$ concentration declined.

\section{MATERIALS AND METHODS}

Cell isolation. Goldfish (Carassius auratus) were killed by severing the cervical spinal cord and pithing the brain, following guidelines of the University of Chicago Institutional Animal Care and Use Committee. The procedure for dissociating a retina and maintaining solitary cells was similar to that described by Bader et al. (1982). Solitary bipolar cells were identified by their characteristic morphology (Fig. 1).

In our initial experiments, dissociated cells were plated into dishes whose bottom was a glass coverslip. A styryl dye stained cells and adsorbed to the glass coverslip. Unbinding of the dye from the coverslip was very slow. Quantitative measurement of vesicle cycling was difficult when images were contaminated by a large background signal. Fortunately, unbinding of the dye was much faster when cells were plated onto a coverslip that had been coated with a thin layer of silicone plastic (Sylgard 184; Dow Corning, Midland, MI). Cells adhered to the silicone plastic if it was first covered with $0.25 \mathrm{mg} \mathrm{ml}^{-1}$ concanavalin A in $1 \mathrm{M}$ $\mathrm{NaCl}$ for $20 \mathrm{~min}$, rinsed with distilled water, and air dried.

The extracellular saline contained (in $\mathrm{mM}$ ): $\mathrm{NaCl}, 120 ; \mathrm{KCl}, 2.5$; $\mathrm{CaCl}_{2}, 0.2 ; \mathrm{MgCl}_{2}, 1$; Na-pyruvate, 2; Na-lactate, 2; glucose, 10; and HEPES, 10; the $\mathrm{pH}$ was adjusted to 7.4 with $\mathrm{NaOH}$, and the saline was supplemented with vitamins $(1: 100)$ and amino acids $(1: 100)$ formulated for Eagle's minimum essential medium (Life Technologies, Gaithersburg, MD). The osmolality was $\sim 260 \mathrm{mOsm} \mathrm{kg}^{-1}$. Cells were loaded with fura-2 by incubating in normal extracellular saline supplemented with $2 \mu \mathrm{M}$ fura-2 AM plus $16 \mu \mathrm{M}$ pluronic acid for $1 \mathrm{hr}$. For some experiments (see Fig. 4), cells were loaded with mag-fura- 5 and fluo- 3 by incubating in $1 \mu \mathrm{M}$ mag-fura-5 AM, $1 \mu \mathrm{M}$ fluo-3 AM, plus $16 \mu \mathrm{M}$ pluronic acid for $1 \mathrm{hr}$. Experiments were performed at $20-23^{\circ} \mathrm{C}$.

Optical system and image analysis. Light from a $75 \mathrm{~W}$ Xe short arc lamp was used to excite dye fluorescence. Excitation wavelength was selected with a filter changer (Lambda 10-2; Sutter Instruments, Novato, CA) containing narrow-band $(15 \mathrm{~nm})$ interference filters with transmission maxima at 331, 380, and $485 \mathrm{~nm}$. The filtered light was reflected into a microscope with a $510 \mathrm{~nm}$ dichroic mirror and was imaged by an objective (Fluar 40x/1.3; Carl Zeiss) to a 150- $\mu$ m-diameter spot centered in the field of view. The maximum intensity within this spot was $1.4 \mathrm{~W} \mathrm{~m}^{-2}$ at $331 \mathrm{~nm}, 5.6 \mathrm{~W} \mathrm{~m}^{-2}$ at $380 \mathrm{~nm}$, and $180 \mathrm{~W} \mathrm{~m}^{-2}$ at $485 \mathrm{~nm}$. Fluorescent light collected by the objective passed through a second filter changer containing a $520-580 \mathrm{~nm}$ bandpass filter or an RG630 Schott glass long-pass filter before being imaged onto a CCD camera (model AT200; Photometrics, Tucson, AZ). Each pixel imaged a $0.16 \mu \mathrm{m} \times 0.16 \mu \mathrm{m}$ region in the plane of focus. The operation of shutters and filter wheels was controlled by a computer. Because of overlap in both their excitation 


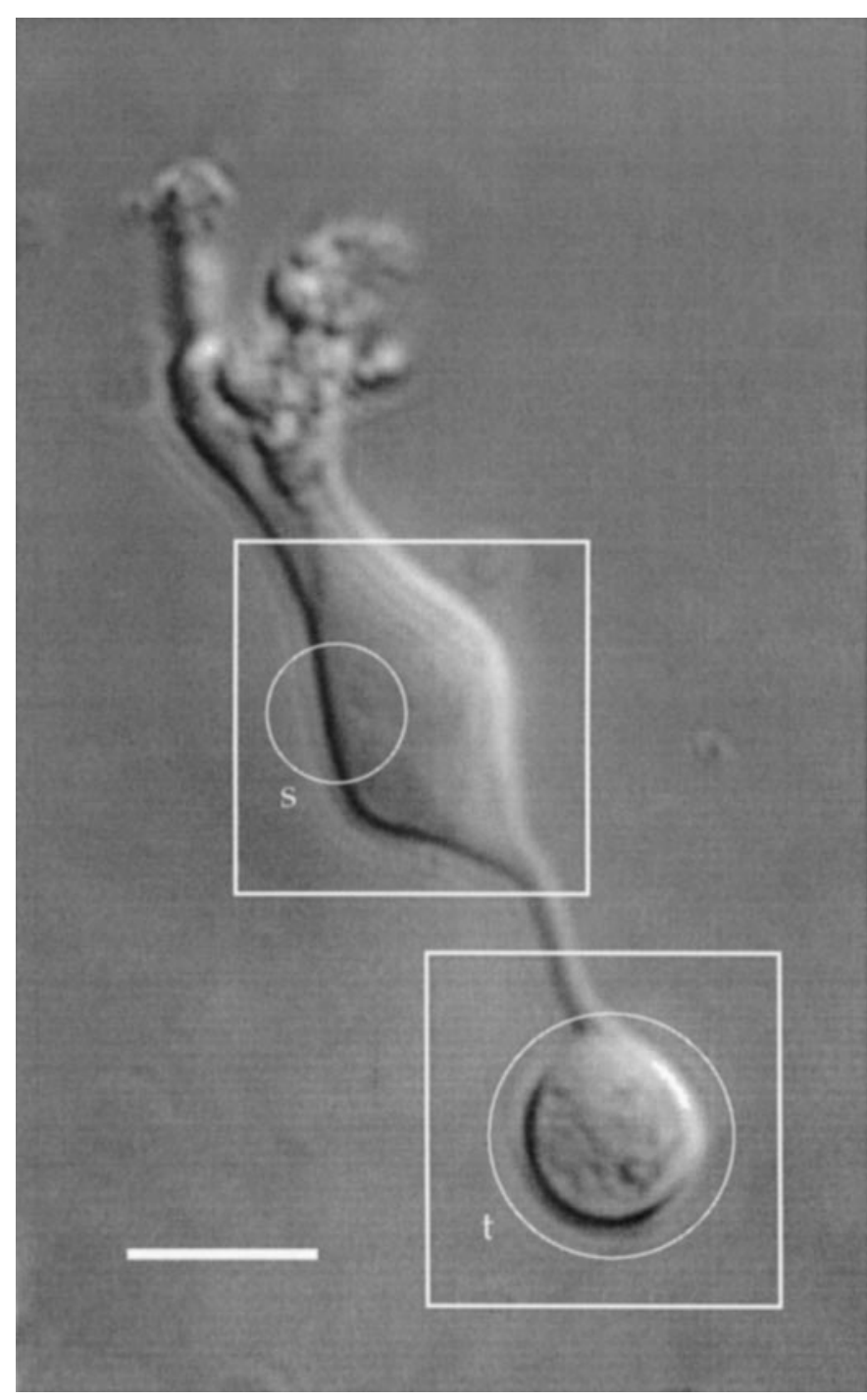

Figure 1. Hoffman modulation micrograph of a solitary bipolar cell. The squares indicate regions of interest that were saved during an experiment. The circles indicate areas in which the total fluorescence was measured (see text). Scale bar, $10 \mu \mathrm{m}$.

and emission spectra, fluo-3 and FM1-43 were not used together in the same experiment. Control experiments demonstrated that the combinations of wavelengths, light intensities, and dye concentrations actually used in the experiments allowed the interleaved measurement of $\mathrm{Ca}^{2+}$ concentration and either FM1-43 or FM4-64 fluorescence without crossover between the signals. In some experiments we used both FM1-43 and FM4-64. In these experiments, we corrected for the crossover of light emitted by FM1-43 in the FM4-64 detection band (see Fig. 3).

At the beginning of each experiment, a Hoffman interference image of the entire cell was recorded (Fig. 1), and two regions of interest $\sim 20 \mu \mathrm{m}$ square were selected (Fig. 1, outlined by squares). One region included the synaptic terminal; the other region included a portion of the soma. Fluorescent images of the two regions produced by $100 \mathrm{msec}$ exposures were collected for the required filter combinations and saved for later analysis.

Normally, several movies were made after an experiment was completed. For example, the measurement of $\mathrm{Ca}^{2+}$ concentration and FM1-43 fluorescence required six movies. One movie (produced by 485 nm exciting light) imaged FM1-43 fluorescence in the terminal. Second (produced by $331 \mathrm{~nm}$ light) and third (produced by $380 \mathrm{~nm}$ light) movies imaged fura-2 fluorescence in the terminal and were used to calculate the average, cytoplasmic $\mathrm{Ca}^{2+}$ concentration. A similar set of three movies imaged FM1-43 and fura-2 fluorescence in the soma. The ability to identify potential problems was greatly facilitated by recording a movie of fluorescent images instead of integrating all of the light in a microscope field with a photomultiplier tube. Preliminary experiments demonstrated that bright 331 and $380 \mathrm{~nm}$ lights adversely affected the morphology of stained cells. Consequently, light intensity and repetition rate for fura-2 and mag-fura-5 measurements were minimized. We rejected the rare experiments in which a cell significantly changed shape.

The total fluorescence in the terminal was measured by summing the intensities in pixels within a circular area slightly larger than the terminal (Fig. 1, circle designated $t$ ). The fluorescence in the soma was measured by summing the intensities of pixels within a circular subregion $\sim 8 \mu \mathrm{m}$ in diameter over a portion of the soma (Fig. 1, circle designated $s$ ). Background fluorescence of FM1-43 and FM4-64, measured in a region $\sim 5$ $\mu \mathrm{m}$ distant from a cell, was subtracted from each pixel. For the calcium indicator dyes, background fluorescence measured away from the cell was negligible.

We assumed that the fluorescence of dye molecules was unchanged during endocytosis. Results (see Figs. 5, 10) indicate that vesicles quickly diffused throughout a terminal. Because vesicles appeared to be uniformly distributed, we were able to use the fluorescence in an optical section to calculate the total amount of endocytosed membrane distributed throughout a terminal. A microscope objective collects light from an image depth of $4 \lambda /(\mathrm{NA})^{2}$, where $\lambda$ is the wavelength of light and NA is the numerical aperture of the objective. Hence the thickness of an optical section was 1.4-1.6 $\mu \mathrm{m}$ for experiments that imaged FM1-43 or FM464 . Because these values are much less than the $10 \mu \mathrm{m}$ diameter of a terminal, the geometry can be described as a plane intersecting a sphere. If $\kappa_{p}$ is the ratio of the area of a circular disk to the length of its perimeter and $\kappa_{s}$ is the ratio of the volume of a sphere to its surface area, then we can measure $\kappa_{p}$ and estimate $\kappa_{s}$ after multiplying by a geometrical correction factor, $\rho=\kappa_{s} / \kappa_{p}=2 / 3$. Because bipolar cell somata are not spherical, a similar procedure is not appropriate. Instead, results from somata are in arbitrary units and have been scaled to facilitate a qualitative comparison.

Calcium measurement. The fluorescence of fura- 2 or mag-fura- 5 was excited by light of 331 and $380 \mathrm{~nm}$. Emission was detected between 520 and $580 \mathrm{~nm}$. Intracellular $\mathrm{Ca}^{2+}$ concentration was calculated from the relation (Grynkiewicz et al., 1985): $\left[\mathrm{Ca}^{2+}\right]=k \beta\left(R-R_{\min }\right) /\left(R_{\max }-R\right)$, where $R$ is the ratio of the fluorescence intensity excited at $331 \mathrm{~nm}$ divided by the intensity excited at $380 \mathrm{~nm}, R_{\max }$ is the ratio produced by a saturating $\mathrm{Ca}^{2+}$ concentration, $R_{\min }$ is the ratio produced by a minimum concentration, $\beta$ is the ratio of emission intensity stimulated at 380 $\mathrm{nm}$ in the absence of $\mathrm{Ca}^{2+}$ to that in the presence of an excess of $\mathrm{Ca}^{2+}$, and $k$ is an apparent affinity constant. Affinity constants were determined by superfusing 20 cells with either $10 \mu \mathrm{M}$ ionomycin or $10 \mu \mathrm{M} \mathrm{A} 23187$ and a series of $\mathrm{Ca}^{2+}$ concentrations set with $\mathrm{Ca}^{2+}$ buffers (see below). Each concentration was superfused until a steady state was achieved. The affinity constant was $237 \mathrm{nM}$ for fura- 2 and $10 \mu \mathrm{M}$ for mag-fura-5. $R_{\min }$, $R_{\max }$, and $\beta$ were measured for each cell. $R_{\min }$ was estimated at the beginning of each experiment while a cell was superfused with a low $\mathrm{Ca}^{2+}$ concentration; $R_{\max }$ and $\beta$ were measured by superfusing at the end of each experiment with saline containing $10 \mu \mathrm{M}$ ionomycin, $4 \mathrm{mM}$ $\mathrm{Ca}^{2+}, 40 \mathrm{~mm} \mathrm{~K}^{+}$, and $1 \mu \mathrm{M}$ BayK8466.

The $485 \mathrm{~nm}$ light excited fluo-3. Emission was detected between 520 and $580 \mathrm{~nm}$. The $\mathrm{Ca}^{2+}$ concentration was calculated from the relation (Grynkiewicz et al., 1985): $\left[\mathrm{Ca}^{2+}\right]=k\left(F-F_{\min }\right) /\left(F_{\max }-F\right)$, where $F$ is the fluorescence intensity, $F_{\min }$ is produced by a minimum $\mathrm{Ca}^{2+}$ concentration, $F_{\max }$ is produced by a saturating $\mathrm{Ca}^{2+}$ concentration, and $k$ is the apparent affinity constant. Minimum and maximum fluorescence were measured as described above for the ratiometric dyes. The affinity constant for fluo-3, also measured as described above, was $0.9 \mu \mathrm{M}$ (see also Rieke and Schwartz, 1996).

Solutions and control of $\mathrm{Ca}^{2+}$ concentration. During an experiment, a cell was continuously superfused with solutions ejected from a fourbarrelled pipette. Each barrel ended in a $\sim 50 \mu \mathrm{M}$ square opening. Each barrel was connected to a reservoir and pressure head through a solenoid valve. Solution changes were made by simultaneously opening and closing valves. Control experiments with fluorescent dyes demonstrated that solution changes were $95 \%$ complete in $<100 \mathrm{msec}$. When an experiment required five different solutions, an additional single-barrelled pipette was used.

The superfused solutions were similar to the extracellular saline described above. $\mathrm{Ca}^{2+}$ concentrations were set with $\mathrm{Ca}^{2+}$ buffers; $1 \mathrm{~mm}$ bis(2-aminophenoxy)ethane- $N, N, N^{\prime}, N^{\prime}$-tetra-acetic acid (BAPTA) was used for free $\mathrm{Ca}^{2+}$ concentrations between 0.1 and $2 \mu \mathrm{M}$, and $1 \mathrm{~mm}$ 

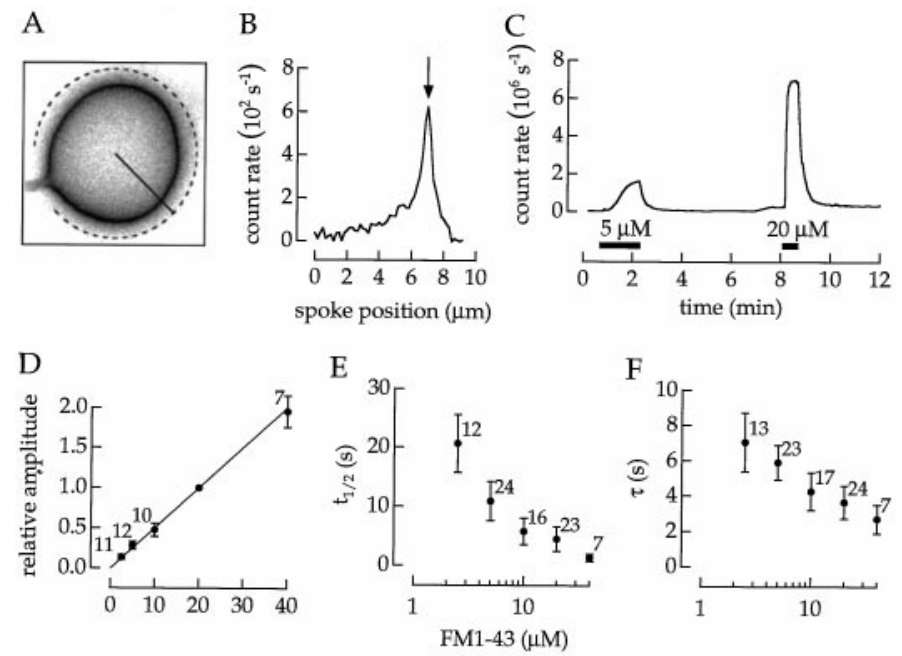

Figure 2. Kinetics of membrane staining depended on dye concentration. $A$, Image of a terminal stained with $20 \mu \mathrm{M}$ FM1-43. $B$, The intensity of pixels along the solid line in $A$ plotted as a function of radial distance. The arrow indicates the location of the surface membrane. $C$, The intensity in the surface membrane plotted as a function of time. The cell was superfused with two concentrations of FM1-43 as indicated by the horizontal bars. The peak intensity along a radial spoke (see $B$ ) was integrated around the circumference, except for the region from which the axon arose (as indicated by the dotted line in $A$ ). $D$, Intensity of membrane staining as a function of dye concentration. $E$, The $t_{1 / 2}$ for the onset of staining as a function of dye concentration. $F$, Apparent exponential time constant for destaining as a function of dye concentration.

$N$-(2-acetamido)-2-iminodiacetic acid (ADA) was used for concentrations between 10 and $200 \mu \mathrm{M}$. Concentrations above $200 \mu \mathrm{M}$ were unbuffered. Salines containing ionomycin and ADA lacked $\mathrm{Mg}^{2+}$. A high $\mathrm{Ca}^{2+}$ and $\mathrm{K}^{+}$saline contained (in $\mathrm{mM}$ ): $\mathrm{NaCl}, 82.5 ; \mathrm{KCl}, 40 ; \mathrm{CaCl}_{2}, 4$; and $\mathrm{MgCl}_{2}, 1$; pyruvate, lactate, glucose, and HEPES levels were as in the normal saline. Experiments were conducted on only one cell in a dish.

The concentration of BAPTA or ADA in stock solutions used to make $\mathrm{Ca}^{2+}$ buffers was determined by titrating with $1.0 \mathrm{~N} \mathrm{CaCl}_{2}$ (BDH Laboratory Supplies) and measuring the free $\mathrm{Ca}^{2+}$ concentration with a $\mathrm{Ca}^{2+}$ electrode. After the concentration of each stock solution was known, salines with a specific free $\mathrm{Ca}^{2+}$ concentration were made according to recipes calculated with the computer program MAXC v1.70 (Bers et al., 1994).

Kinetics of membrane staining. The kinetics of membrane staining depended on the dye concentration. Our procedure for measuring the kinetics is explained in Figure 2. An image of a stained terminal is shown in Figure $2 A$. The intensity of pixels along the radial solid line is plotted in Figure $2 B$. The maximum intensity occurs at the surface membrane (Fig. $2 B$, arrow). To increase the accuracy with which the intensity of membrane fluorescence is measured, we rotated the inclination of the radial line and integrated the membrane signal around the terminal circumference excluding the segment containing the axon (as indicated by the dotted line in Fig. $2 A$ ). The intensity of membrane fluorescence was measured in a sequence of images and plotted as a function of time (Fig. 2C). The cell was exposed to two concentrations of FM1-43, first 5 and then $20 \mu \mathrm{M}$. When the dye was applied, the membrane stained with a nonexponential time course. When the dye was removed, the membrane destained with an approximately exponential time course.

The procedure illustrated in Figure 2, $A-C$, was used to obtain the data in Figure 2, $D-F$. In each experiment, a cell was exposed to two dye concentrations. To compare experiments, we normalized the steady state fluorescence to the intensity produced by $20 \mu \mathrm{M}$ FM1-43. The intensity of membrane staining was proportional to dye concentration (Fig. 2D). The time to the half-maximum amplitude $t_{1 / 2}$ decreased approximately in inverse proportion to the concentration (Fig. 2E). Destaining was approximately described by a single exponential with a time constant that also depended on concentration (Fig. $2 F$ ).

A linear relation between dye concentration and fluorescence intensity indicates that the number of dye molecules in the membrane is not

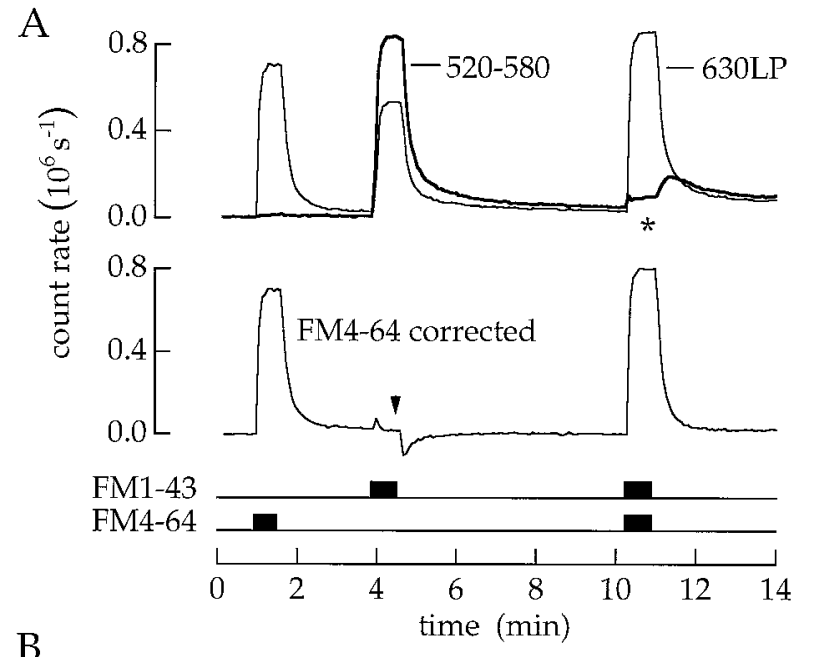

B

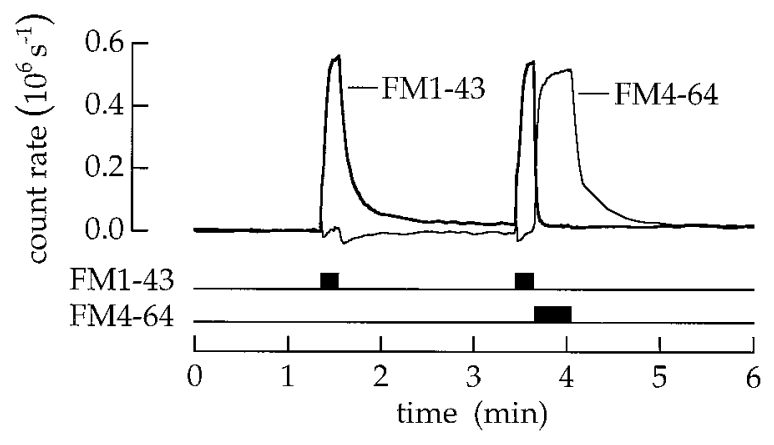

Figure 3. FM4-64 quenched FM1-43 fluorescence. Bipolar cells were superfused with $20 \mu \mathrm{M}$ FM1-43, $20 \mu \mathrm{M}$ FM4-64, or both dyes together as indicated (superfusions in this and the following figures indicated by horizontal bars). A, The upper pair of superimposed traces is the fluorescence measured in the two detection channels. The thick trace is the fluorescence detected between 520 and $580 \mathrm{~nm}$; the thin trace is the fluorescence detected with a $630 \mathrm{~nm}$ long-pass filter. When the two dyes are given together, the fluorescence of FM1-43 (asterisk) was less than that when FM1-43 was delivered alone. FM4-64 fluorescence, estimated by subtracting the crossover of FM1-43 fluorescence into the $630 \mathrm{~nm}$ channel, is plotted in the lower trace. The small glitches in the corrected trace (arrowhead) are produced because two spectral components of FM1-43 fluorescence leave the membrane at different rates. The time constants for FM1-43 destaining are $6.7 \mathrm{sec}$ (thick trace) and $3.5 \mathrm{sec}$ (thin trace). B, FM4-64 can be used to improve the resolution of membrane destaining. The thick trace is the intensity for emission between 520 and $580 \mathrm{~nm}$. When FM1-43 was delivered alone, the time constant of membrane destaining was $6.7 \mathrm{sec}$. When FM1-43 was followed by a pulse of FM4-64, fluorescence of FM1-43 in the surface membrane disappeared in $<1.4 \mathrm{sec}$.

limited by a small and fixed number of binding sites. A simple model would describe the movement of dye into the membrane as the partitioning between an aqueous and lipid phase accomplished in a single kinetic step. However, in this case, staining and destaining would have exponential time courses that are independent of concentration. This was not the case. The nonexponential time course for staining and a change in kinetics with dye concentration indicate that dye molecules equilibrate in a series of states.

The time course of membrane staining and destaining will obviously limit the time resolution for measurements of vesicle cycling. A concentration of $20 \mu \mathrm{M}$ provided a reasonable resolution for membrane staining. However, to observe membrane destaining with a resolution finer than several tens of seconds, we needed an additional technique.

Resonance energy transfer. We have discovered an easy method to increase the time resolution of membrane destaining. FM4-64 rapidly quenched the fluorescence of FM1-43. An example is shown in Figure $3 A$. A bipolar cell was superfused first with FM4-64, next with FM1-43, 
and finally with both dyes together. The emission intensities in the two detection channels are superimposed in Figure $3 A$ (upper traces). Crossover from FM1-43 into the FM4-64 detection channel (Fig. 3A, thin upper trace) was measured, and the corrected trace is plotted below. The essential observation came when the two dyes were applied together. Now, the fluorescence of FM1-43 was strongly quenched (Fig. 3A, asterisk). Dye intensity was reduced $94 \%$. In addition, there was an apparent 14\% increase in FM4-64 fluorescence. This behavior suggested the procedure in Figure $3 B$. First, a cell was superfused with a pulse of FM1-43. When the dye was removed, fluorescence in the FM1-43 channel (Fig. 3B, thick trace) declined with a time constant of 6.7 sec. Next, a pulse of FM1-43 was immediately followed by a pulse of FM4-64. Now, FM1-43 fluorescence was quickly quenched. The fluorescence in the surface membrane disappeared in $<1.4 \mathrm{sec}$.

Sources and abbreviations. Ionomycin, FM1-43, FM4-64, fluo-3 AM, fura-2 AM, and mag-fura-5 AM were obtained from Molecular Probes (Eugene, OR). Papain was purchased from Worthington (Freehold, NJ). All other chemicals were obtained from Sigma (St. Louis, MO)..

\section{RESULTS}

FM1-43 is a lipophilic dye that partitions into cell membranes. The dye has little fluorescence in aqueous solution and is much more fluorescent in a membrane environment. Positive charges are believed to prevent dye molecules from flipping between the outer and the inner membrane leaflet. Consequently, extracellular FM1-43 has been used to tag the outer leaflet of the surface membrane and then to visualize the bits that are pulled into the cytoplasm by endocytosis (Betz et al., 1992, 1996). However, as described in the Appendix, the ability of dye to cross the cell membrane can complicate its use as a membrane tag. We designed experiments to minimize this problem.

\section{$\mathrm{Ca}^{2+}$ dependence of continuous vesicle cycling}

To explore the relation between $\mathrm{Ca}^{2+}$ concentration and vesicle cycling, we adopted two strategies to produce a nearly uniform change in intracellular $\mathrm{Ca}^{2+}$ concentration. The first procedure relied on a $\mathrm{Ca}^{2+}$ ionophore, ionomycin, and the entry of $\mathrm{Ca}^{2+}$ from the extracellular saline. The second procedure relied on a proton ionophore, monensin, and the release of $\mathrm{Ca}^{2+}$ from intracellular, acidic organelles. Both procedures were able to raise the cytoplasmic $\mathrm{Ca}^{2+}$ concentration.

For the first procedure, cells were superfused with ionomycin $(10 \mu \mathrm{M})$ and a $\mathrm{Ca}^{2+}$ buffer. Changing the free $\mathrm{Ca}^{2+}$ concentration in the extracellular saline was followed by a change in the intracellular concentration. During a typical 1-3 min application, the intracellular concentration reached $3-25 \%$ of the extracellular concentration. An example is illustrated in Figure 4. The cell was first superfused with ionomycin and $100 \mathrm{nM} \mathrm{Ca}^{2+}$. The addition of FM4-64 (Vida and Emr, 1995) stained the surface membrane and produced a fluorescence change (labeled $s$ ). Next, when the extracellular $\mathrm{Ca}^{2+}$ concentration was increased to 50 $\mu \mathrm{M}$, the intracellular concentration followed with a rise to $\sim 1.7$ $\mu \mathrm{M}$. At the same time, the fluorescence of FM4-64 increased (labeled $v_{x}$ ). We believe that the increase in fluorescence is produced as exocytosis adds vesicle membrane to the surface membrane. The rate of continuous exocytosis $C_{x}$ was calculated as $C_{x}=\rho v_{x} / s \Delta t$, where $\rho$ is a geometrical constant (see Materials and Methods) and $\Delta t$ is the time interval in which $v_{x}$ was measured. $C_{x}$ has units of membrane equivalents (abbreviated MEq) per unit time. Raising the intracellular concentration from 0.09 to $1.7 \mu \mathrm{M}$ increased $C_{x}$ from 0.01 to $0.33 \mathrm{MEq} \mathrm{min}^{-1}$. At the same time, there was little change in the fluorescence imaged from the soma.

We expected the rate of vesicle cycling to increase with the $\mathrm{Ca}^{2+}$ concentration. Surprisingly, when the experiment was con-

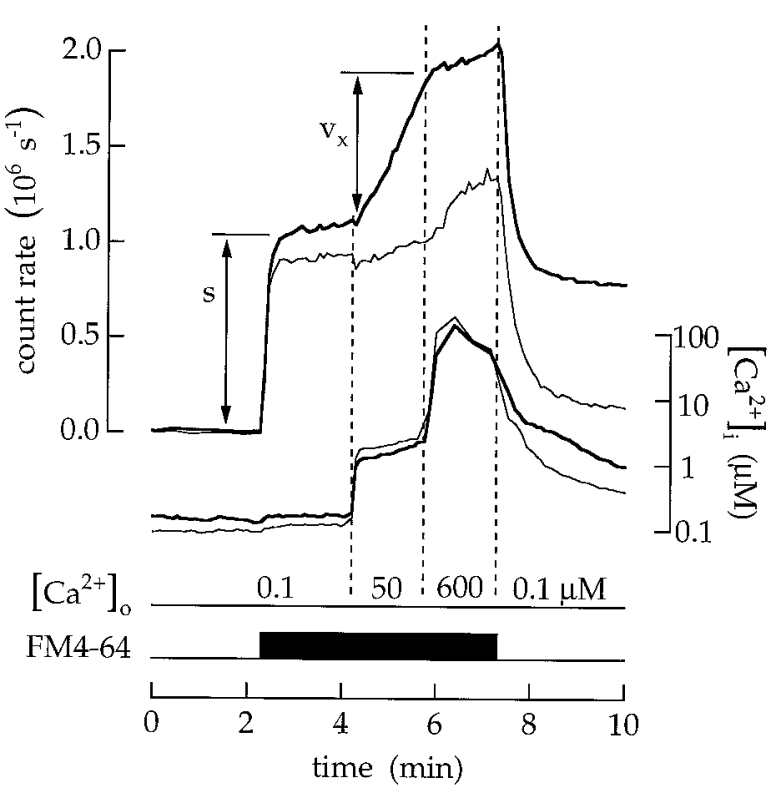

Figure 4. Continuous exocytosis is stimulated by a low $\mathrm{Ca}^{2+}$ concentration and inhibited by a high $\mathrm{Ca}^{2+}$ concentration. Cells were continuously superfused with salines containing $10 \mu \mathrm{M}$ ionomycin. The fluorescence intensity produced by $20 \mu \mathrm{M}$ FM4-64 is plotted by the upper set of traces; the intracellular $\mathrm{Ca}^{2+}$ concentration is plotted by the lower set of traces. Thick traces in this and the following figures were measured in the terminal; thin traces were measured in the soma. Continuous exocytosis was measured as $C_{x}=\rho v_{x} / s \Delta t$. Salines containing $100 \mathrm{nM}, 50 \mu \mathrm{M}$, and 600 $\mu \mathrm{M}$ extracellular $\mathrm{Ca}^{2+}$ were applied as indicated by the dashed vertical lines. $\mathrm{Ca}^{2+}$ concentrations below $10 \mu \mathrm{M}$ were reported by fluo-3; concentrations above $10 \mu \mathrm{M}$ were reported by mag-fura-5. Increasing the intracellular $\mathrm{Ca}^{2+}$ from 0.09 to $1.7 \mu \mathrm{M}$ increased $C_{x}$ to $0.33 \mathrm{MEq} \mathrm{min}{ }^{-1}$. A further rise in the intracellular $\mathrm{Ca}^{2+}$ to between 50 and $140 \mu \mathrm{M}$ reduced $C_{x}$ to $0.06 \mathrm{MEq} \min ^{-1}$.

tinued by increasing the extracellular $\mathrm{Ca}^{2+}$ concentration to 600 $\mu \mathrm{M}$, the intracellular concentration rose to between 50 and 140 $\mu \mathrm{M}$, and the rate of FM4-64 fluorescence change actually declined. In this experiment $C_{x}$ was reduced from 0.33 to $0.06 \mathrm{MEq}$ $\min ^{-1}$. A similar result was observed in 21 experiments.

Images acquired during an experiment provide information about the fate of membrane added to the surface by exocytosis. The following experiment used the ability of FM4-64 to quench the fluorescence of FM1-43 in the surface membrane (see Materials and Methods; Fig. 3). Afterward, we quickly observed the distribution of FM1-43-labeled vesicles in the cytoplasm (Fig. 5). Image $a$ was recorded $24 \mathrm{sec}$ after the terminal was stained with FM1-43. At this moment the $\mathrm{Ca}^{2+}$ concentration was $\sim 1 \mu \mathrm{M}$. The profile of the terminal is nearly round and smooth. Image $b$ was taken $68 \mathrm{sec}$ later, when the intracellular $\mathrm{Ca}^{2+}$ concentration had increased to $4 \mu \mathrm{M}$. Small patches of fluorescence are located immediately beneath the surface membrane, the surface contour itself is slightly irregular with sites of local expansion or dilation, and the interior of the terminal has a uniform weak fluorescence. Finally, image $c$ was taken $15 \mathrm{sec}$ after the fluorescence in the surface membrane was quenched so that only the fluorescence of FM1-43 in endocytosed vesicles was detected. The fluorescence of FM1-43 was almost uniformly distributed, indicating that endocytosed vesicles quickly diffused throughout the cytoplasm.

The rate of steady endocytosis was estimated by first raising the intracellular $\mathrm{Ca}^{2+}$ concentration and then measuring the amount of FM1-43 accumulated during a $12 \mathrm{sec}$ test pulse (Fig. 6). The rate of continuous endocytosis $C_{n}$ was calculated as $C_{n}=\rho v_{n} / s \Delta t$, 


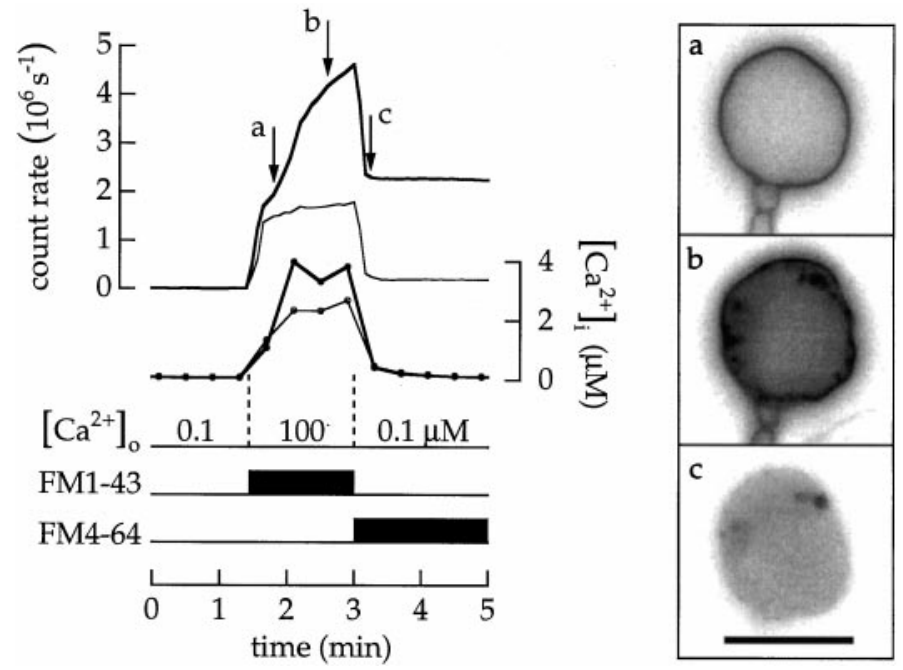

Figure 5. Endocytosed vesicles quickly diff use throughout the terminal. Cells were superfused with $10 \mu \mathrm{M}$ ionomycin and $\mathrm{Ca}^{2+}$ buffers. $a-c$, Images recorded at the times marked by the arrows are at the right. Intracellular $\mathrm{Ca}^{2+}$ concentration in this and the following figures was reported by fura-2 fluorescence. The cell was superfused first with $100 \mathrm{nM}$ $\mathrm{Ca}^{2+}$, then with $20 \mu \mathrm{M}$ FM1-43 in a saline containing $100 \mu \mathrm{M} \mathrm{Ca}^{2+}$, and finally with $20 \mu \mathrm{M}$ FM4-64 in a saline containing $100 \mathrm{nM} \mathrm{Ca}^{2+}$. Scale bar, $10 \mu \mathrm{m}$.

where $v_{n}$ is defined in the figure. For the two measurements in Figure 6 , the $\mathrm{Ca}^{2+}$ concentration was $1.3 \mu \mathrm{M}$, and $C_{n}$ was 0.33 and

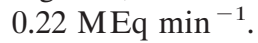

Figures 4 and 6 provide two methods for measuring rates of continuous vesicle cycling. A summary of 102 experiments is presented in Figure 7. Crosses were measured by the procedure in Figure 4; closed symbols were measured by the procedure in Figure 6. Vesicle cycling in the terminal was not observed at $\mathrm{Ca}^{2+}$ concentrations below $0.8 \mu \mathrm{M}$. A high rate of cycling was sustained at $\mathrm{Ca}^{2+}$ concentrations between 0.8 and $20 \mu \mathrm{M}$. Increasing the $\mathrm{Ca}^{2+}$ concentration above $20 \mu \mathrm{M}$ decreased the rate of cycling. The maximum rate of vesicle cycling in Figure 7 was $\sim 0.5 \mathrm{MEq} \min ^{-1}$. Because the membrane surface area of a terminal (with a diameter of $10 \mu \mathrm{m}$ ) is 110,000 times the surface area of a $30 \mathrm{~nm}$ synaptic vesicle, this corresponds to a rate of 900 vesicles $\mathrm{sec}^{-1}$.

Ionomycin allowed $\mathrm{Ca}^{2+}$ to enter the cytoplasm from the extracellular saline. An alternative procedure was to raise intracellular $\mathrm{Ca}^{2+}$ without a change in extracellular $\mathrm{Ca}^{2+}$ concentration. For this purpose we used monensin, an ionophore that disrupts the $\mathrm{pH}$-dependent accumulation of $\mathrm{Ca}^{2+}$ in intracellular organelles (Fasolato et al., 1991). The subsequent release of $\mathrm{Ca}^{2+}$ raises cytoplasmic $\mathrm{Ca}^{2+}$ concentration. The procedure is illustrated in Figure 8. The cell was continuously superfused with an extracellular saline containing $100 \mathrm{nM} \mathrm{Ca}^{2+}$ (and no ionomycin). When $2 \mu \mathrm{M}$ monensin was added, the $\mathrm{Ca}^{2+}$ concentration in the terminal cytoplasm increased transiently to nearly $6 \mu \mathrm{M}$. This increase in $\mathrm{Ca}^{2+}$ concentration was not produced by an influx from the extracellular saline (where the $\mathrm{Ca}^{2+}$ concentration was only $100 \mathrm{~nm}$ ) but was instead produced by the release of $\mathrm{Ca}^{2+}$ from intracellular organelles. The rise in $\mathrm{Ca}^{2+}$ concentration was accompanied by an increase in FM4-64 fluorescence. A similar result was observed in eight experiments.

Both the experiments with ionomycin and monensin demonstrate that a rise in intraterminal $\mathrm{Ca}^{2+}$ concentration to between

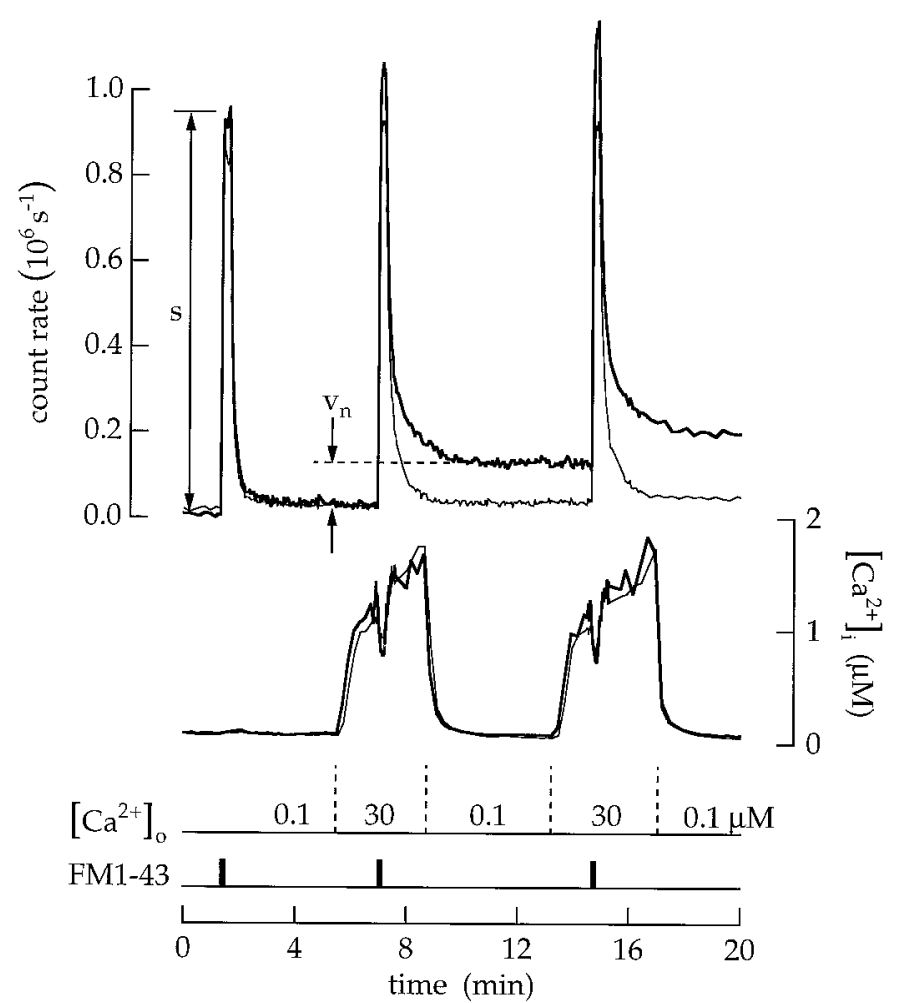

Figure 6. Continuous endocytosis is stimulated by a low $\mathrm{Ca}^{2+}$ concentration. A bipolar cell was continuously superfused with salines containing $10 \mu \mathrm{M}$ ionomycin. The timing bars indicate $12 \mathrm{sec}$ applications of $20 \mu \mathrm{M}$ FM1-43. The cell was superfused first with a saline containing $100 \mathrm{nM}$ $\mathrm{Ca}^{2+}$ and then with $30 \mu \mathrm{M} \mathrm{Ca}^{2+}$ as indicated. $s$ is the fluorescence intensity of the surface membrane; $v_{n}$ is the fluorescence that remains trapped in the cytoplasm and is attributed to endocytosis. The rate of continuous endocytosis $C_{n}$ was measured as $C_{n}=\rho v_{n} / s \Delta t$. For the two measurements, $C_{n}$ was 0.33 and $0.22 \mathrm{MEq} \min ^{-1}$.

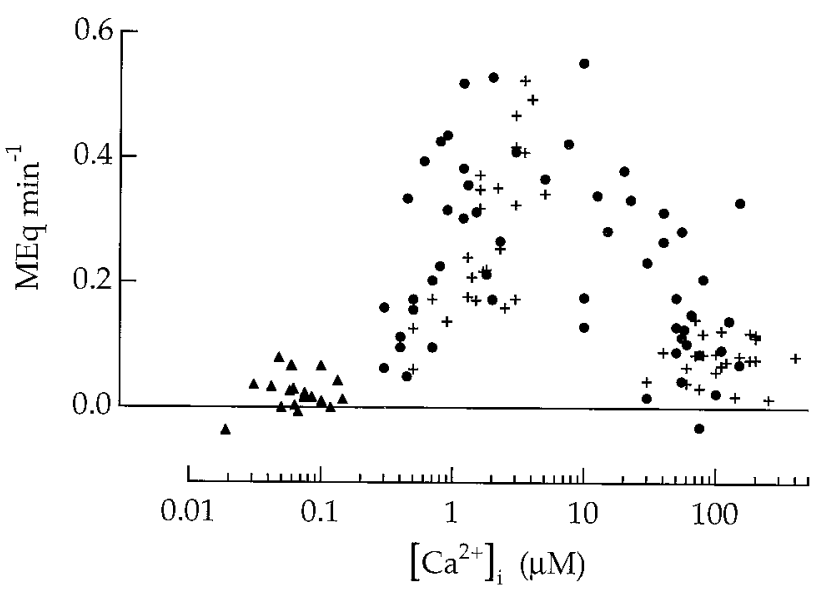

Figure 7. Rate of continuous vesicle cycling in bipolar cell terminals plotted as a function of the intracellular $\mathrm{Ca}^{2+}$ concentration. Circles are for measurements of endocytosis from 60 cells permeabilized with ionomycin as described in Figure 6. Triangles are for 18 unpermeabilized cells measured during the resting state by the same procedure. Crosses are for measurements of exocytosis from 24 cells measured by the procedure illustrated in Figure 4. 

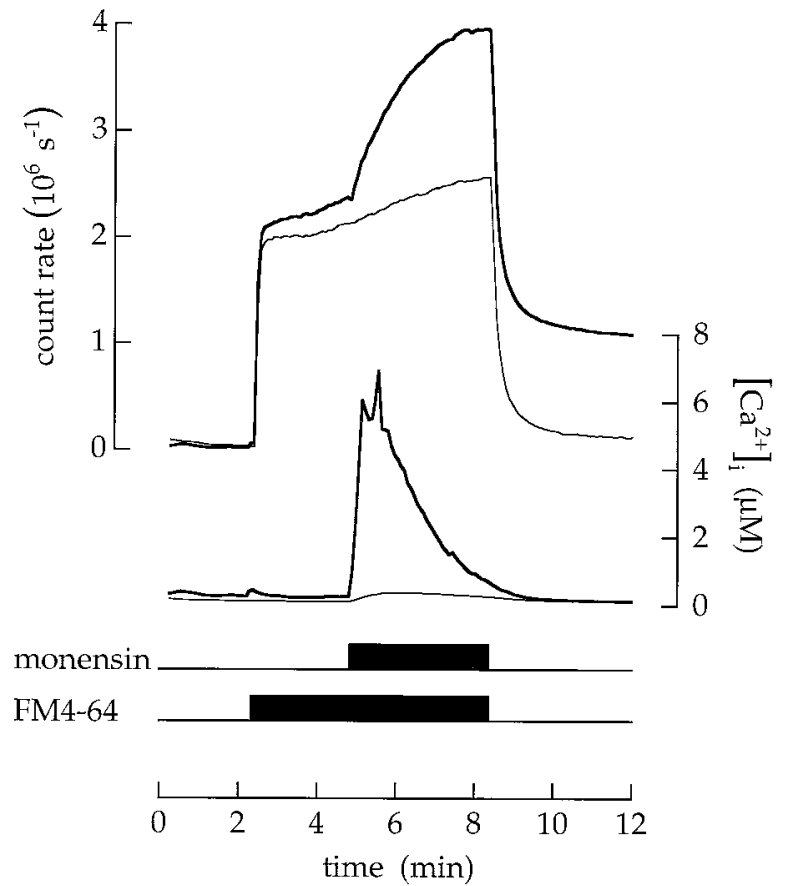

Figure 8. The release of $\mathrm{Ca}^{2+}$ from intracellular organelles raises the cytoplasmic $\mathrm{Ca}^{2+}$ concentration and stimulates exocytosis. The cell was continuously superfused with an extracellular saline buffered to contain $100 \mathrm{nM}$ free $\mathrm{Ca}^{2+}$. The lower timing trace indicates the application of 20 $\mu \mathrm{M}$ FM4-64. The upper timing trace indicates the addition of $2 \mu \mathrm{M}$ monensin.

0.8 and $20 \mu \mathrm{M}$ produced a continuous cycle of vesicle exocytosis and endocytosis. The maximum rate was sufficient to turn over the surface membrane of a terminal every $2 \mathrm{~min}$.

\section{Transient vesicle cycling initiated by $\mathrm{Ca}^{2+}$ entry through voltage-gated channels}

Normally, fusion is triggered when $\mathrm{Ca}^{2+}$ enters through voltagegated channels. $\mathrm{Ca}^{2+}$ first accumulates at the cytoplasmic end of each open channel and then diffuses into the cytoplasm. The result is many small domains of high $\mathrm{Ca}^{2+}$ concentration that quickly dissolve. The following experiments investigated vesicle cycling triggered by depolarization and $\mathrm{Ca}^{2+}$ influx. In each experiment, cells were initially superfused with a saline containing $100 \mathrm{nM} \mathrm{Ca}^{2+}$ (to minimize premature $\mathrm{Ca}^{2+}$ entry during a control period). Exocytosis was triggered by superfusion with a saline containing $4 \mathrm{~mm} \mathrm{Ca}^{2+}$ and $40 \mathrm{~mm} \mathrm{~K}^{+}$.

Exocytosis induced by depolarization and $\mathrm{Ca}^{2+}$ influx is illustrated in Figure 9. First, FM4-64 stained the surface membrane (labeled $s$ ). Next, a 4 sec exposure to the high $\mathrm{Ca}^{2+}$ and $\mathrm{K}^{+}$saline depolarized, increased the average $\mathrm{Ca}^{2+}$ concentration in the terminal, and produced a step increase in FM4-64 fluorescence (labeled $v_{x}$ ). We assume that the abrupt increase in the fluorescence of the terminal was proportional to the membrane added to the surface by exocytosis. The amount of exocytosis $T_{x}$ was calculated as $T_{x}=\rho v_{x} / s$. In Figure $9, T_{x}$ was 0.13 and $0.08 \mathrm{MEq}$. In contrast, depolarization did not increase fluorescence in the soma (Fig. 9, thin trace). In 25 experiments $T_{x}$ varied from being barely detectable to $\sim 0.13 \mathrm{MEq}$.

The previous measurements were confirmed by observing endocytosis. Cells were first superfused with a saline containing 100 nм Ca ${ }^{2+}$ to minimize $\mathrm{Ca}^{2+}$ entry and to prevent $\mathrm{Ca}^{2+}$-triggered vesicle cycling. An $18 \mathrm{sec}$ exposure to FM1-43 stained the surface
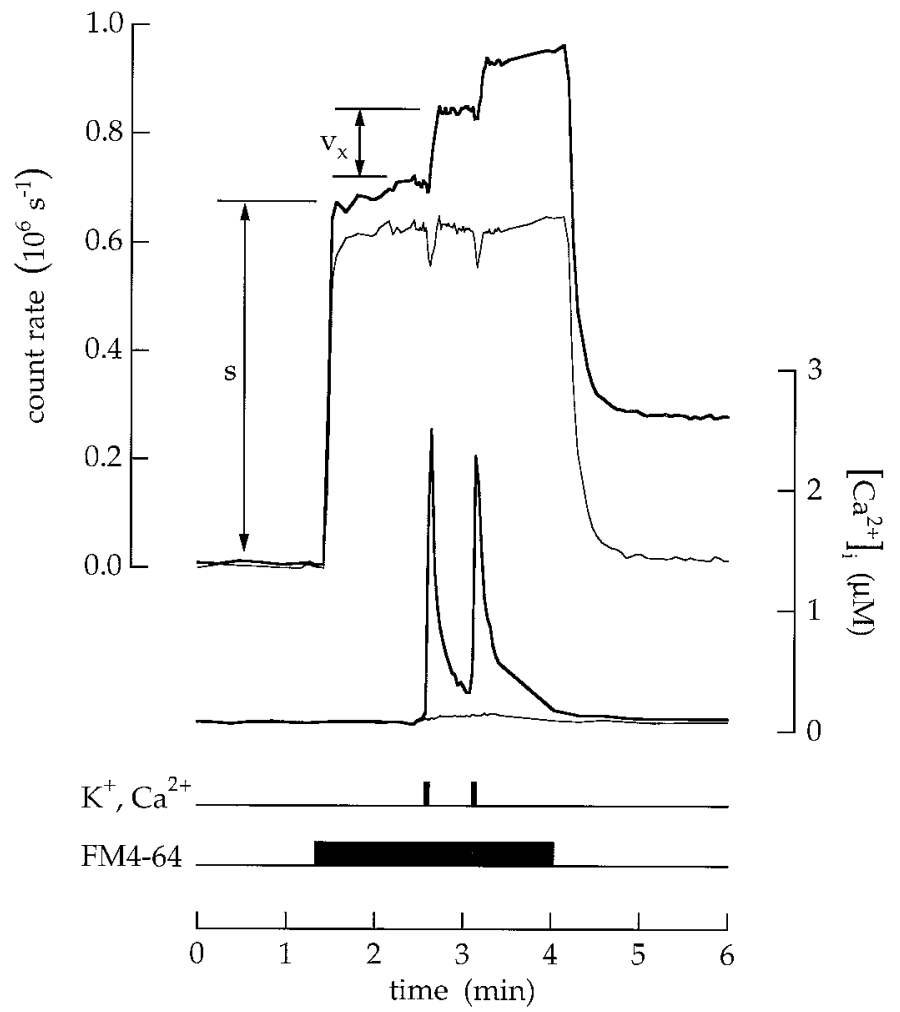

Figure 9. Exocytosis was induced by depolarization and $\mathrm{Ca}^{2+}$ influx. A bipolar cell was superfused with an extracellular saline containing $100 \mathrm{nM}$ $\mathrm{Ca}^{2+}$. The lower timing trace indicates the application of $20 \mu \mathrm{M}$ FM4-64. The upper timing trace indicates $4 \mathrm{sec}$ applications of a high $\mathrm{Ca}^{2+}$ and $\mathrm{K}^{+}$ saline $\left(4 \mathrm{mM} \mathrm{Ca}^{2+}\right.$ and $\left.40 \mathrm{mM} \mathrm{K}^{+}\right) \cdot v_{x}$ is the intensity increase produced by vesicle exocytosis. Transient exocytosis $T_{x}$ was measured as $T_{x}=\rho v_{x} / s$. For the two applications of high $\mathrm{Ca}^{2+}$ and $\mathrm{K}^{+}$saline, $T_{x}$ was 0.13 and 0.08 MEq.

membrane of the terminal (Fig. 10, thick upper trace). As expected, a 6 sec exposure to high $\mathrm{Ca}^{2+}$ and $\mathrm{K}^{+}$saline produced a $\mathrm{Ca}^{2+}$ influx and raised the average cytoplasmic $\mathrm{Ca}^{2+}$ concentration (thick lower trace). After FM1-43 was removed from the extracellular saline, the surface membrane destained, and fluorescence remained trapped in the cytoplasm of the terminal (labeled $v_{n}$ ). The amount of endocytosis $T_{n}$ was measured as $T_{n}=$ $\rho v_{n} / s$. In this case, $T_{n}$ was $0.08 \mathrm{MEq}$. In contrast, little or no dye was trapped in the soma (Fig. 10, thin upper trace). In addition, no endocytosis occurred when FM4-64 was applied as a control at the end of the experiment (Fig. 10, middle traces). In 22 experiments $T_{n}$ was $0.049 \pm 0.030 \mathrm{MEq}$ (equal to 5500 vesicles). The largest values were $\sim 0.12 \mathrm{MEq}$ (equal to 13,000 vesicles).

Images of the terminal are shown in two insets in Figure 10. Image $a$ was taken during the time the membrane was stained with FM1-43. Image $b$ was taken after the dye was removed and the membrane destained. There is no evidence of localization of newly endocytosed vesicles beneath the surface membrane. Instead, stained vesicles appear to be uniformly distributed throughout the interior of the terminal.

A second application of high $\mathrm{Ca}^{2+}$ and $\mathrm{K}^{+}$saline without dye did not release a significant fraction of the labeled vesicles. We were never able to label vesicles, destain the surface membrane, and then release the accumulated dye in a second bout of vesicle cycling. Of course, this is not surprising if newly endocytosed vesicles diffuse rapidly and mix with the entire intraterminal 


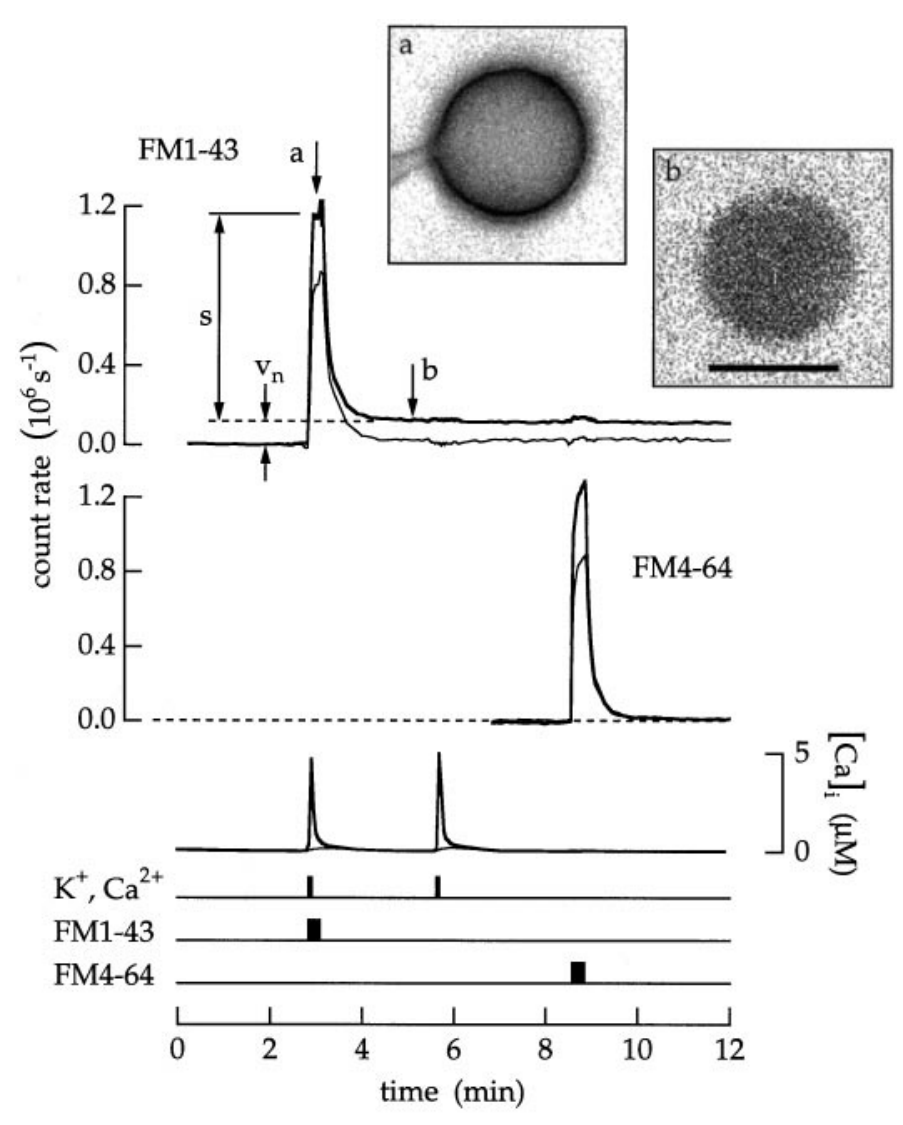

Figure 10. Endocytosis was induced by depolarization and $\mathrm{Ca}^{2+}$ influx. A bipolar cell was superfused with an extracellular saline containing 100 $\mathrm{nM} \mathrm{Ca}{ }^{2+}$. Timing traces indicate an $18 \mathrm{sec}$ application of $20 \mu \mathrm{M}$ FM1-43, an $18 \mathrm{sec}$ application of $20 \mu \mathrm{M} \mathrm{FM} 4-64$, and $6 \mathrm{sec}$ applications of a high $\mathrm{Ca}^{2+}$ and $\mathrm{K}^{+}$saline. $s$ is the fluorescence intensity of the surface membrane. $v_{n}$ is the fluorescence of endocytosed vesicles that remain trapped in the cytoplasm. Transient endocytosis was measured as $T_{n}=$ $\rho v_{n} / s$. After superfusion with the high $\mathrm{Ca}^{2+}$ and $\mathrm{K}^{+}$saline, $T_{n}$ was 0.08 MEq. Insets, Images of the terminal taken at the times marked $a$ and $b$ are shown. The gain in $b$ is eight times the gain in $a$. Scale bar, $10 \mu \mathrm{m}$.

vesicle population. A single burst of exocytosis typically labeled $\sim 10,000$ vesicles. For comparison, a terminal contains $5-10 \times 10^{5}$ vesicles (see von Gersdorff et al., 1996). Thus, only 1-2\% would be labeled, and a decrease in fluorescence by a second bout of exocytosis would be difficult to measure.

Vesicle cycling induced by depolarization depended on $\mathrm{Ca}^{2+}$ entry through voltage-gated $\mathrm{Ca}^{2+}$ channels and stopped when $\mathrm{Ca}^{2+}$ channels were blocked. An example is shown in Figure 11. The cell was exposed to high $\mathrm{Ca}^{2+}$ and $\mathrm{K}^{+}$saline three times. The first exposure produced a bout of endocytosis with $T_{n}=0.08$ MEq. Afterward, $50 \mu \mathrm{M}$ nisoldipine was added to the solutions containing FM1-43 to block voltage-gated channels (see Heidelberger and Matthews, 1992). The subsequent application of high $\mathrm{Ca}^{2+}$ and $\mathrm{K}^{+}$saline plus nisoldipine produced a much smaller change in the average intraterminal $\mathrm{Ca}^{2+}$ concentration. Evidently, most $\mathrm{Ca}^{2+}$ channels were blocked. At the same time, there was little endocytosis, and $T_{n}=0.006 \mathrm{MEq}$ (or a reduction of $92 \%)$. A repeated application of high $\mathrm{Ca}^{2+}$ and $\mathrm{K}^{+}$saline plus nisoldipine produced a similar, barely detectable increase in the average $\mathrm{Ca}^{2+}$ concentration and $T_{n}=0.003 \mathrm{MEq}$. Increasing the extracellular concentrations of $\mathrm{K}^{+}$and $\mathrm{Ca}^{2+}$ while pharmacologically blocking $\mathrm{Ca}^{2+}$ influx did not produce vesicle cycling. The

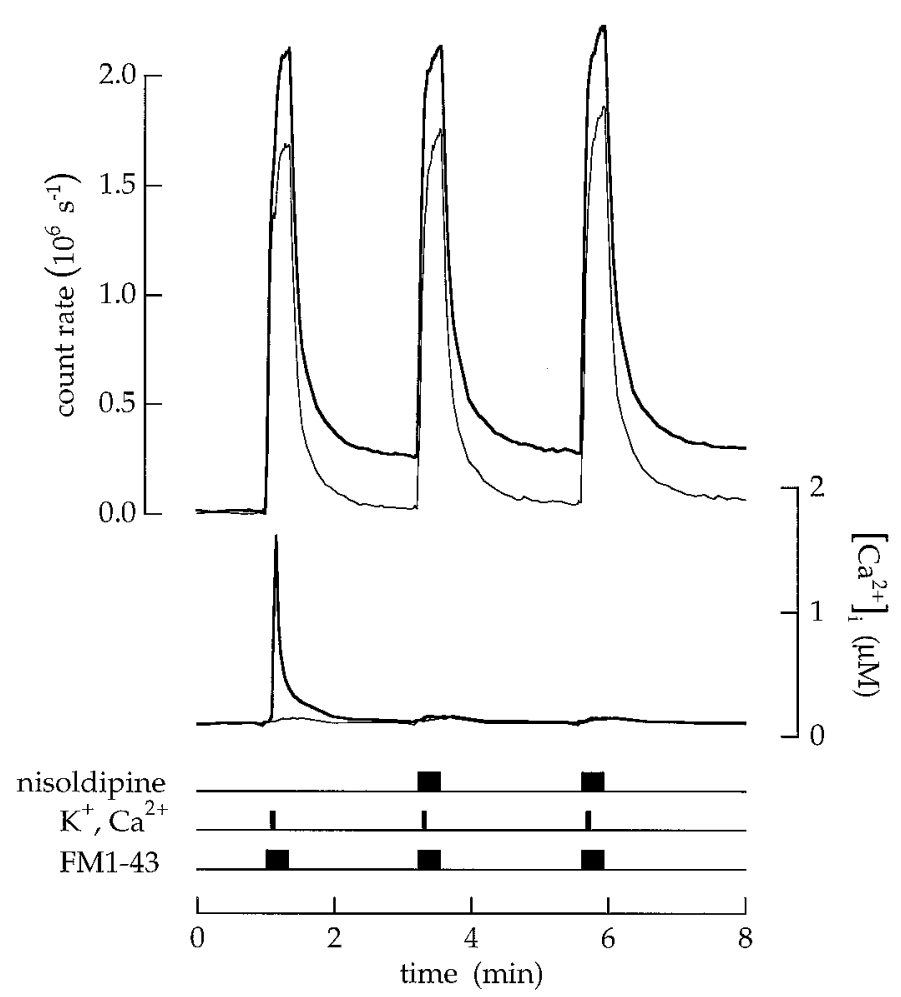

Figure 11. Pharmacologically blocking voltage-gated $\mathrm{Ca}^{2+}$ channels blocked $\mathrm{Ca}^{2+}$ influx and endocytosis. A bipolar cell was superfused first with an extracellular saline containing $100 \mathrm{nM} \mathrm{Ca}^{2+}$ and then three times with FM1-43 and high $\mathrm{Ca}^{2+}$ and $\mathrm{K}^{+}$saline. Each application was a sequence of $20 \mu \mathrm{M}$ FM1-43 in control saline for $4 \mathrm{sec}$, FM1-43 in high $\mathrm{Ca}^{2+}$ and $\mathrm{K}^{+}$saline for $4 \mathrm{sec}$, and finally FM1-43 in control saline for 12 sec. Nisoldipine $(50 \mu \mathrm{M})$ was added to the extracellular salines during the second and third applications. $T_{n}$ (measured as illustrated in Fig. 10) for the three sequential applications was $0.08,0.006$, and $0.003 \mathrm{MEq}$.

same result was observed in 11 experiments. Depolarization stimulated vesicle cycling only when $\mathrm{Ca}^{2+}$ was able to influx through voltage-gated channels.

We were next interested to know whether $\mathrm{Ca}^{2+}$ influx through voltage-gated channels produced a relatively steady rate of vesicle cycling or a burst of cycling that developed quickly and soon subsided. Long and short episodes of $\mathrm{Ca}^{2+}$ entry were promoted by superfusing with a saline containing high $\mathrm{Ca}^{2+}$ and $\mathrm{K}^{+}$. An example is shown in Figure 12. After a $3 \mathrm{sec}$ exposure to high $\mathrm{Ca}^{2+}$ and $\mathrm{K}^{+}$saline, $T_{n}(3)$ was $0.11 \mathrm{MEq}$. Lengthening the depolarization to $15 \mathrm{sec}$ produced a very similar value; $T_{n}(15)=$ $0.12 \mathrm{MEq}$. Finally, the $15 \mathrm{sec}$ exposure was repeated with $1 \mu \mathrm{M}$ BayK8466 added to the high $\mathrm{Ca}^{2+}$ and $\mathrm{K}^{+}$saline to prolong the open time of $\mathrm{Ca}^{2+}$ channels (see Heidelberger and Matthews, 1992). As expected, the average cytoplasmic $\mathrm{Ca}^{2+}$ concentration rose to a higher level, but $T_{n}$ was still $0.11 \mathrm{MEq}$. In 15 experiments the ratio $T_{n}(3) / T_{n}(15)$ was $1.06 \pm 0.49$. Each pulse of high $\mathrm{Ca}^{2+}$ and $\mathrm{K}^{+}$produced an approximately equal increment in dye accumulation. An experiment described above (see Fig. 10) demonstrates that labeled vesicles quickly mixed with a $100 \times$ larger vesicle pool. Consequently, only $\sim 1 \%$ of the vesicles labeled during one bout of cycling were released in a subsequent bout of cycling, and each increment represents labeled vesicles added in a new round of exocytosis with little loss of previously accumulated vesicles. Thus, equal steps of accumulation indicate that the majority of exocytosis initiated by superfusion with a high $\mathrm{Ca}^{2+}$ and $\mathrm{K}^{+}$saline is completed in a single, transient burst. 


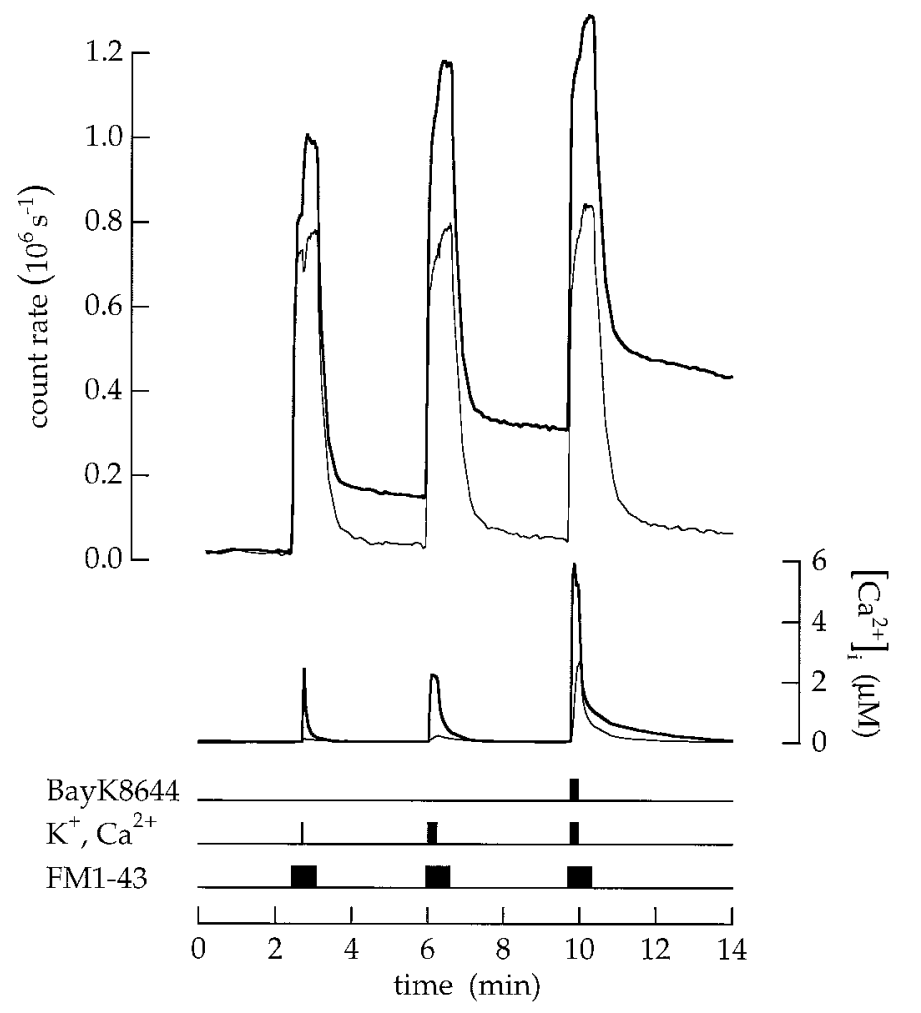

Figure 12. Vesicle cycling triggered by $\mathrm{Ca}^{2+}$ influx was transient. The cell was superfused three times with a $30 \mathrm{sec}$ pulse of $20 \mu \mathrm{M}$ FM1-43. Transient endocytosis $T_{n}$ was measured as shown in Figure 10. The first application included a $3 \mathrm{sec}$ pulse of high $\mathrm{Ca}^{2+}$ and $\mathrm{K}^{+} ; T_{n}=0.11 \mathrm{MEq}$. The second application included a $15 \mathrm{sec}$ pulse of high $\mathrm{Ca}^{2+}$ and $\mathrm{K}^{+} ; T_{n}$ $=0.12 \mathrm{MEq}$. The third application was similar but added $1 \mu \mathrm{M}$ BayK8466 to the high $\mathrm{Ca}^{2+}$ and $\mathrm{K}^{+}$saline to prolong the open time of $\mathrm{Ca}^{2+}$ channels; $T_{n}=0.11 \mathrm{MEq}$. Increasing the duration or amount of $\mathrm{Ca}^{2+}$ entry did not alter transient exocytosis. The control saline contained 100 $\mathrm{nM} \mathrm{Ca}{ }^{2+}$. Each pulse of FM1-43 extended $12 \mathrm{sec}$ beyond the end of the high $\mathrm{Ca}^{2+}$ and $\mathrm{K}^{+}$application.

Capacitance measurements by von Gersdorff and Matthews (1994b) indicate that endocytosis does not occur while the $\mathrm{Ca}^{2+}$ concentration is elevated. The following experiment (Fig. 13) provides additional insight. A cell was exposed to two pulses of high $\mathrm{Ca}^{2+}$ and $\mathrm{K}^{+}$saline. The first application was used to identify the amounts of endocytosis that occurred first during and then after $\mathrm{Ca}^{2+}$ entry. At the end of the first application, the exposure to FM1-43 and the high $\mathrm{Ca}^{2+}$ and $\mathrm{K}^{+}$saline ended together, and FM1-43 fluorescence in the surface membrane was quenched with FM4-64. Vesicles endocytosed during exposure to high $\mathrm{Ca}^{2+}$ and $\mathrm{K}^{+}$saline should be labeled with FM1-43, but vesicles endocytosed after the return to the low $\mathrm{Ca}^{2+}$ saline should be labeled with FM4-64. $T_{n}$ measured by the FM1-43 pulse was only $0.004 \mathrm{MEq}$. $T_{n}$ measured by the FM4-64 pulse was $0.05 \mathrm{MEq}$. The second application of FM1-43 was used to measure the total amount of endocytosis. Exposure to FM1-43 continued $12 \mathrm{sec}$ beyond the $6 \mathrm{sec}$ pulse of high $\mathrm{Ca}^{2+}$ and $\mathrm{K}^{+}$ saline. Consequently, vesicles endocytosed both during and after the pulse of $\mathrm{Ca}^{2+}$ and $\mathrm{K}^{+}$saline were labeled with FM1-43. In this case $T_{n}$ was $0.07 \mathrm{MEq}$. The entire experiment indicates that little endocytosis occurred during superfusion with high $\mathrm{Ca}^{2+}$ and $\mathrm{K}^{+}$saline but that a significant amount occurred after return to the control saline.

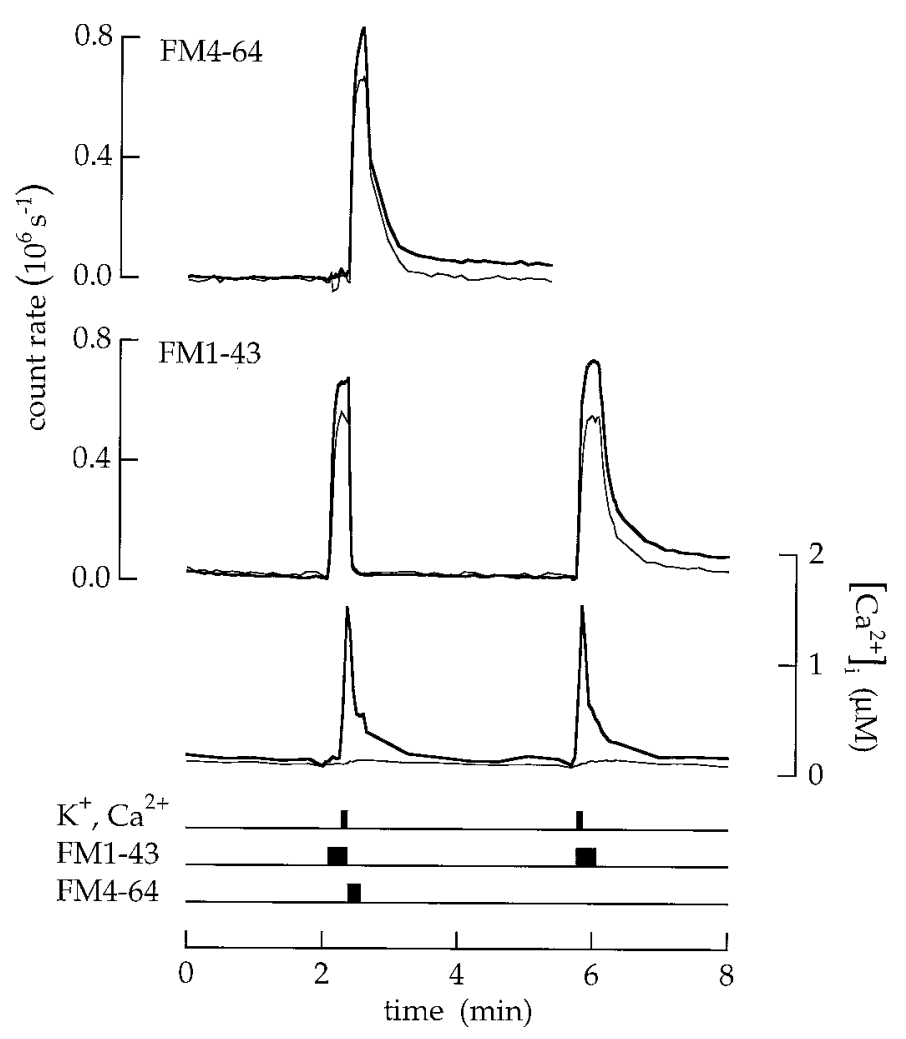

Figure 13. Endocytosis was delayed until after $\mathrm{Ca}^{2+}$ influx stopped. The timing of endocytosis was measured with $18 \mathrm{sec}$ applications of $20 \mu \mathrm{M}$ FM1-43 combined with $6 \mathrm{sec}$ pulses of high $\mathrm{Ca}^{2+}$ and $\mathrm{K}^{+}$saline. The first applications of FM1-43 and high $\mathrm{Ca}^{2+}$ and $\mathrm{K}^{+}$saline ended together and were immediately followed by a pulse of $20 \mu \mathrm{M}$ FM4-64 in a saline containing $100 \mathrm{nM} \mathrm{Ca}^{2+}$. The FM4-64 quenched the fluorescence of FM1-43 in the surface membrane (see Fig. 3) but not in vesicles trapped in the cytoplasm. $T_{n}$ measured (as shown in Fig. 10) with FM1-43 was $0.004 \mathrm{MEq}$ and indicated that little endocytosis occurred during superfusion with the high $\mathrm{Ca}^{2+}$ and $\mathrm{K}^{+}$saline. $T_{n}$ measured with FM4-64 was $0.05 \mathrm{MEq}$ and indicated that significant endocytosis occurred after return to the control saline. The second application of FM1-43 measured the total amount of endocytosis; $T_{n}=0.07 \mathrm{MEq}$.

\section{DISCUSSION}

Electrical and optical experiments now provide different perspectives of synaptic vesicle cycling. Both methods have been used to study ribbon synapses in the large synaptic endings of goldfish bipolar cells. Capacitance measurements are best suited to detect rapid events. Heidelberger et al. (1994) have measured the change in electrical capacitance produced when a jump in $\mathrm{Ca}^{2+}$ concentration promotes the rapid fusion of a limited number of vesicles. In contrast, fluorescence from styryl dyes cannot resolve rapid events but is best suited to detect slow, continuous, or maintained changes. As we explain below, the two methods provide complementary views of synaptic vesicle dynamics.

The electrical measurements reveal that a rapid, saturating increase in the intracellular $\mathrm{Ca}^{2+}$ concentration triggers the fusion of $\sim 3000$ vesicles with a time constant of $0.35 \mathrm{msec}$ (Heidelberger et al., 1994), too short for an individual fusion site to be used more than once. Consequently, all 3000 vesicles must be predocked and ready for release. The rate constant for the last step in vesicle fusion accelerates from $1 \mathrm{sec}^{-1}$ when the $\mathrm{Ca}^{2+}$ concentration is $\sim 10 \mu \mathrm{M}$ to $1000 \mathrm{sec}^{-1}$ when the concentration reaches $200 \mu \mathrm{M}$ [see Heidelberger et al. (1994), their Fig. 3a]. The optical measurements reported here demonstrate that a $\mathrm{Ca}^{2+}$ 
concentration between 0.8 and $20 \mu \mathrm{M}$ can maintain a continuous cycle of balanced exocytosis and endocytosis with a maximal rate of 900 vesicles sec $^{-1}$ (Fig. 7) or $\sim 0.3$ vesicle $\sec ^{-1}$ at each release site. The continuous cycle slows when the $\mathrm{Ca}^{2+}$ concentration rises above $20 \mu \mathrm{M}$. Both the electrophysiological and optical measurements demonstrate that $\mathrm{Ca}^{2+}$ influx through voltagegated channels produces a burst of exocytosis but little or no endocytosis until the average $\mathrm{Ca}^{2+}$ concentration falls. Moreover, the maximum number of vesicles released appears to be greater than the number of fusion sites (i.e., 10,000 vesicles vs 3,000 fusion sites), implying that several vesicles fuse at each site before cycling stops.

Our results differ from those of Lagnado et al. (1996). We have observed that (1) depolarization by high $\mathrm{K}^{+}$produces a transient burst of vesicle cycling, (2) newly endocytosed vesicles rapidly diffuse and mix with the total intraterminal vesicle population, and (3) a high rate of continuous cycling is sustained at concentrations between 0.8 and $20 \mu \mathrm{M}$ intracellular $\mathrm{Ca}^{2+}$ and stops at higher concentrations. Lagnado et al. (1996) claim that (1) depolarization by high $\mathrm{K}^{+}$produces continuous vesicle cycling, (2) newly endocytosed vesicles accumulate beneath the surface membrane, and (3) continuous cycling is sustained at all $\mathrm{Ca}^{2+}$ concentrations above $0.3 \mu \mathrm{M} \mathrm{Ca}{ }^{2+}$. We cannot explain these differences.

We expect the function of fusion sites to depend critically on the location of $\mathrm{Ca}^{2+}$ channels and illustrate our view with two examples. One extreme behavior would occur in a "synapse" with only one $\mathrm{Ca}^{2+}$ channel and an immediately adjacent fusion site. In this case, the $\mathrm{Ca}^{2+}$ concentration in a microdomain at the cytoplasmic end of the channel will tightly control vesicle cycling. In contrast, another extreme behavior would occur in a "synapse" with a $\mathrm{Ca}^{2+}$ channel far from a fusion site. In this case, release would be controlled by the average $\mathrm{Ca}^{2+}$ concentration in the cytoplasm. Many channel openings would raise the average cytoplasmic $\mathrm{Ca}^{2+}$ concentration and sustain a continuous cycle of repeated exocytosis and endocytosis. Of course, these idealized synapses illustrate extreme behaviors. But the examples indicate how dynamic behavior may depend on the number and relative spatial distribution of channels and fusion sites. Many central synapses have only one, or a few, fusion sites (see Redman, 1990; Korn and Faber, 1991; Ryan et al., 1997) and consequently may approach either of the two extreme behaviors described above. However, cells with ribbon synapses have many fusion sites (Raviola and Gilula, 1975; von Gersdorff et al., 1996) and, combining the behavior of both models, should mediate both transient and continuous release.

Bipolar cells, like rod photoreceptors (Rieke and Schwartz, 1996), sustain high rates of vesicle cycling at relatively low (0.8-20 $\mu \mathrm{M}) \mathrm{Ca}^{2+}$ concentrations. This is the result of having many release sites that operate in parallel. Although the rate of turnover at an individual release site is estimated as only 0.3 vesicle $\mathrm{sec}^{-1}$, the net effect of simultaneously maintaining release at a large number of sites is an enormous membrane flux, equal in a bipolar cell to the replacement of the entire surface area of a terminal every 2 min. Neurons with ribbon synapses-photoreceptors, hair cells, and retinal bipolar cells-appear to be specialized for the massive, parallel release of many vesicles.

An endocytosed vesicle passes through an uncertain number of intermediate steps before being ready for a new round of fusion. If newly endocytosed vesicles had to be immediately reused, then continuous release would be limited by the time required to produce a mature, fusion-competent vesicle. Significantly, endo-
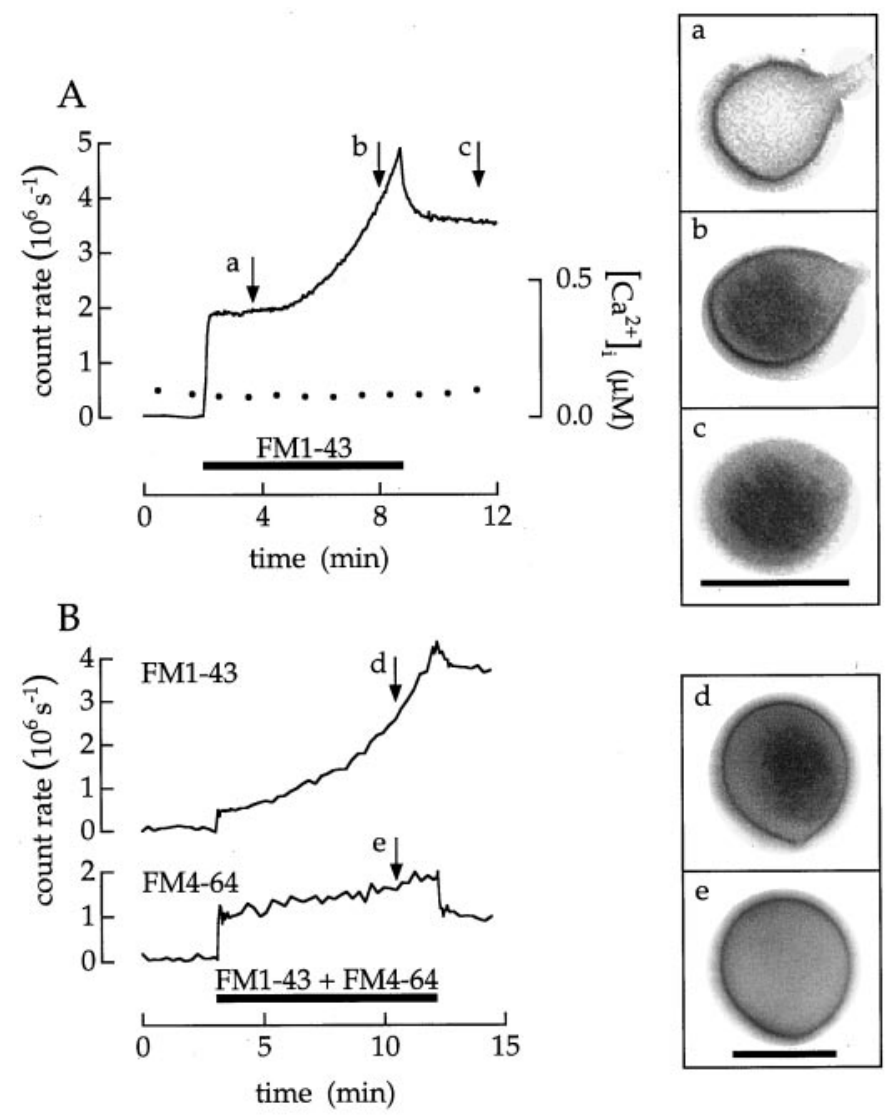

Figure 14. Spontaneous entry of FM1-43. A, The cell was continuously superfused with $10 \mu \mathrm{M}$ ionomycin and $100 \mathrm{nM} \mathrm{Ca}^{2+}$. Intracellular $\mathrm{Ca}^{2+}$ concentration was measured by fura- 2 fluorescence (closed circles). The application of $20 \mu \mathrm{M}$ FM1-43 is indicated by the horizontal timing bar. $a-c$, The three images at the right were taken at the times indicated by arrows. $B$, Dye crosses the membrane of a fixed terminal. The cell was fixed with $2 \%$ formaldehyde for $1 \mathrm{hr}$. The application of $15 \mu \mathrm{M}$ FM1-43 plus $15 \mu \mathrm{M}$ FM4-64 is indicated by the horizontal timing bar. $d, e$, The two images were taken at the time indicated by the arrows. Data were corrected for crossover of FM1-43 fluorescence into the FM4-64 detection band. FM1-43 and FM4-64 accumulated in the cytoplasm with different time courses. Scale bars in $c$ and $e, 10 \mu \mathrm{m}$.

cytosed vesicles are not immobilized near release sites but quickly diff use throughout the terminal (Figs. 5, 10). A total of 5-10 $\times$ $10^{5}$ vesicles (von Gersdorff et al., 1996) is equal to $\sim 500-1000$ vesicles per release site. Hence, vesicles may continuously move to docking sites from an abundant reserve. A large number of release sites and a surfeit of vesicles are required to maintain a high rate of continuous release.

\section{APPENDIX: FM DYES CROSS THE SURFACE MEMBRANE}

When a bipolar cell was superfused with FM1-43 for several minutes, dye sometimes accumulated in the cytoplasm even without stimulation or a change in experimental condition. For example, in Figure $14 A$, a cell was permeabilized with a $\mathrm{Ca}^{2+}$ ionophore $(10 \mu \mathrm{M}$ ionomycin) and continuously superfused with 100 nм $\mathrm{Ca}^{2+}$. The intracellular $\mathrm{Ca}^{2+}$ concentration remained constant at $\sim 100 \mathrm{~nm}$ throughout the experiment. Nonetheless, FM1-43 initially stained the surface membrane and then, after a significant delay, entered the cytoplasm.

The spontaneous entry of dye did not depend on vesicle cycling. Instead, the following experiment demonstrates that it was pro- 
duced by dye molecules crossing the surface membrane. Cells were first fixed with $2 \%$ formaldehyde for $1 \mathrm{hr}$ and afterward superfused with a saline containing both FM1-43 and FM4-64. The result is shown in Figure $14 \mathrm{~B}$. There are two essential observations. First, FM1-43 accumulated in the cytoplasm of a fixed cell. Thus, spontaneous entry did not require vesicle cycling. This conclusion is reinforced by the second observation; FM1-43 accumulated in the cytoplasm with a different time course than did FM4-64. Of course, the two dyes would be accumulated with the same time course if the two dyes tagged the surface membrane and were internalized together in the membrane of endocytosed vesicles. Instead, the accumulation of FM4-64 was much slower. The results are easily explained if FM1-43 molecules cross the lipid bilayer and the other dye, FM4-64, crosses more slowly.

Images recorded during spontaneous dye entry (Fig. 14) differed in two ways from images recorded during vesicle cycling (Fig. 5). First, fluorescent foci did not develop beneath the surface membrane, and the surface contour did not become irregular. Second, dye preferentially accumulated in the center of a terminal and formed a fluorescent spot occupying perhaps half the internal cross-sectional area. A similar central spot developed when FM1-43 was applied to cells that had been permeabilized by a brief exposure to $20 \mu \mathrm{M}$ digitonin (data not shown). Thus, the central spot was a region that avidly stained when free dye was available in the cytoplasm.

Several observations indicate that styryl dyes form a series of states when they partition into membranes. The complex kinetics of membrane staining and destaining observed in Figure 2 indicates that the dye has more than one state in a membrane. In addition, the glitches seen in Figure 3 (at the arrowhead) are produced because spectral components of FM1-43 fluorescence leave the membrane at different rates. The correlation of spectral and kinetic components indicates distinct states. Finally, the ability of FM4-64 to quench FM1-43 indicates that dye molecules can be closely packed (see Stryer, 1978). Hence, dyes may aggregate. Thus, we were not surprised to find that FM1-43 facilitated its own entry. For example, Figure 15 shows the result from a cell superfused with two concentrations of FM1-43. When the cell was first superfused for several minutes with $5 \mu \mathrm{M}$ FM1-43, there was a steady, slow rate of cytoplasmic accumulation (Fig. 15, lower trace). Next, when the concentration was increased to $40 \mu \mathrm{M}$, the rate of entry (normalized by the dye concentration) increased fivefold (viz., from 0.074 to 0.38 MEq $\min ^{-1}$ ).

We believe that dye molecules equilibrate between a series of states. Some of these transitions may be fast and others quite slow. Moreover, some states may depend on or be nucleated by specific membrane molecules. Eventually, dye molecules might cross the surface membrane either by flipping from the outer to the inner leaflet or by interacting with the lipids that surround channels, opening channels, and then passing through the open pore. The experiments in Figure 16, $A$ and $B$, provide a hint for the mechanism of dye entry. Cells were loaded with fura-2 AM and superfused alternately with salines that contained either $2 \mathrm{~mm}$ $\mathrm{Mg}^{2+}$ or $2 \mathrm{mM} \mathrm{Cd}^{2+}$. Fura- 2 was used to detect the entry of $\mathrm{Cd}^{2+}$. Normally, the permeability of $\mathrm{Cd}^{2+}$ is low. Thus, in each of seven control experiments, there was only a small change in the ratio of fura- 2 fluorescence elicited by 331 and $380 \mathrm{~nm}$ light (Fig. $16 A$ ). In contrast, a different picture was observed in eight experiments when a cell was also superfused with FM1-43 (Fig. 16B). Now, fura-2 fluorescence reported a significant increase in intra-

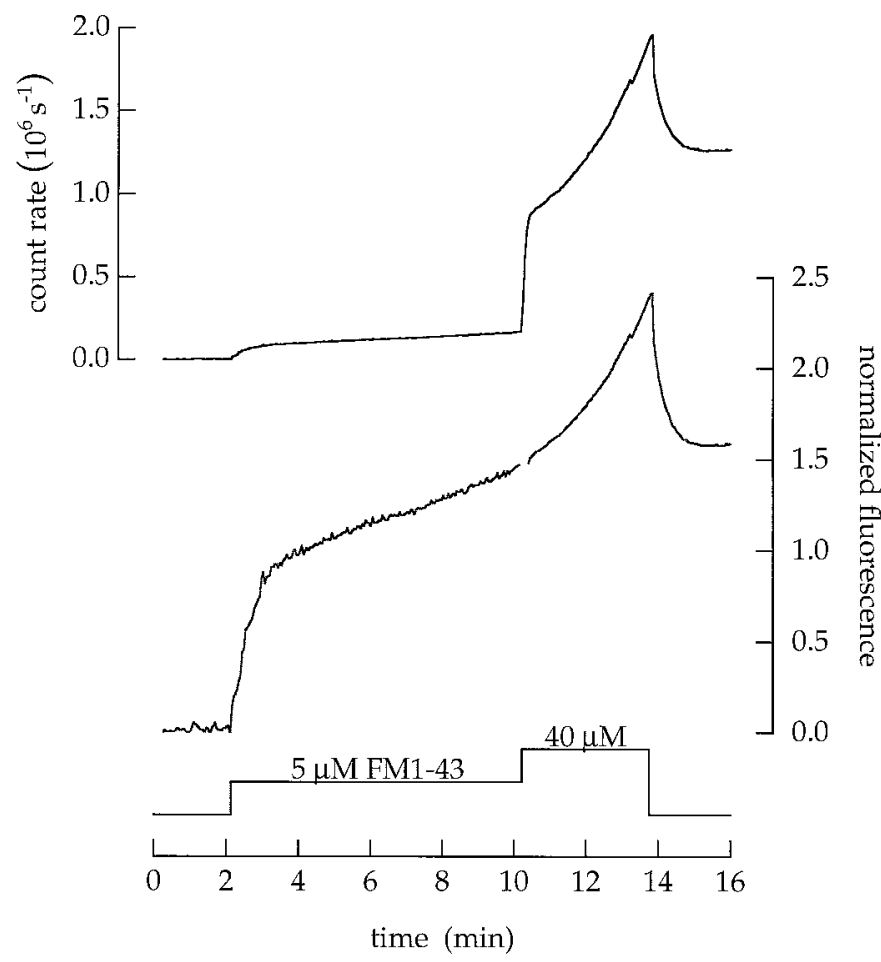

Figure 15. Increasing the FM1-43 concentration facilitates spontaneous entry. A cell was permeabilized with ionomycin and superfused with a saline buffered to contain $100 \mathrm{nM} \mathrm{Ca}^{2+}$. After a control period, 5 and then $40 \mu \mathrm{M}$ FM1-43 were added. Upper trace, Total fluorescence measured in sequential images of the terminal plotted as a function of time. Lower trace, Normalized fluorescence plotted as a function of time. The fluorescence in the surface membrane and that in the cytoplasm (multiplied by the geometric factor $\rho$ ) were summed, normalized by the dye concentration, and then scaled so that the normalized fluorescence in the surface membrane had a value of 1 .

cellular divalent ion concentration each time the cell was exposed to $\mathrm{Cd}^{2+}$. Because the extracellular saline lacked $\mathrm{Ca}^{2+}$, the change in fura-2 fluorescence is attributed to the entry of $\mathrm{Cd}^{2+}$. Thus, continuous exposure to FM1-43 increased the membrane permeability of $\mathrm{Cd}^{2+}$. In addition, each exposure to $\mathrm{Cd}^{2+} \mathrm{de}-$ creased the simultaneous entry of FM1-43 and, after the removal of $\mathrm{Cd}^{2+}$, increased the subsequent entry of FM1-43. Although $\mathrm{Cd}^{2+}$ and FM1-43 interacted in a complex manner, the results imply that both cooperate to increase membrane permeability, most likely by opening a channel.

Experiments on vesicle cycling can be contaminated by spontaneous dye entry. The characteristic delay before rapid intracellular staining was variable. Rapid entry could be triggered by a brief exposure to $\mathrm{Cd}^{2+}$ (Fig. 16), and we have the impression that the transition may sometimes be initiated in the absence of $\mathrm{Cd}^{2+}$ by bright light or exposure to a hydrophobic drug. Once dye entry started, it was not reversible. Therefore, our strategy was (1) to use FM1-43 only for short exposures $(<120 \mathrm{sec}$ in Fig. 5 and $<30$ sec in all other experiments) and FM4-64, which appeared to permeate more slowly (Fig. 14B), for longer exposures, (2) to record images of the terminal in every experiment and to reject an experiment if a bright fluorescent spot formed in the center of the terminal (as in Fig. 14), and (3) to elicit multiple periods of vesicle cycling and to include controls to be certain that all measurements were repeatable. 


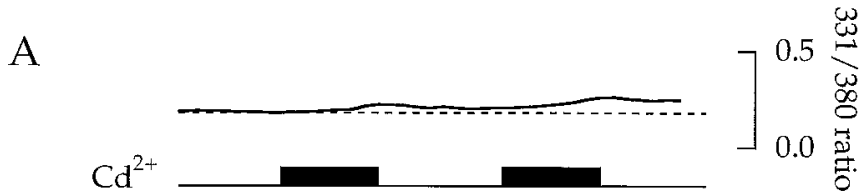

B
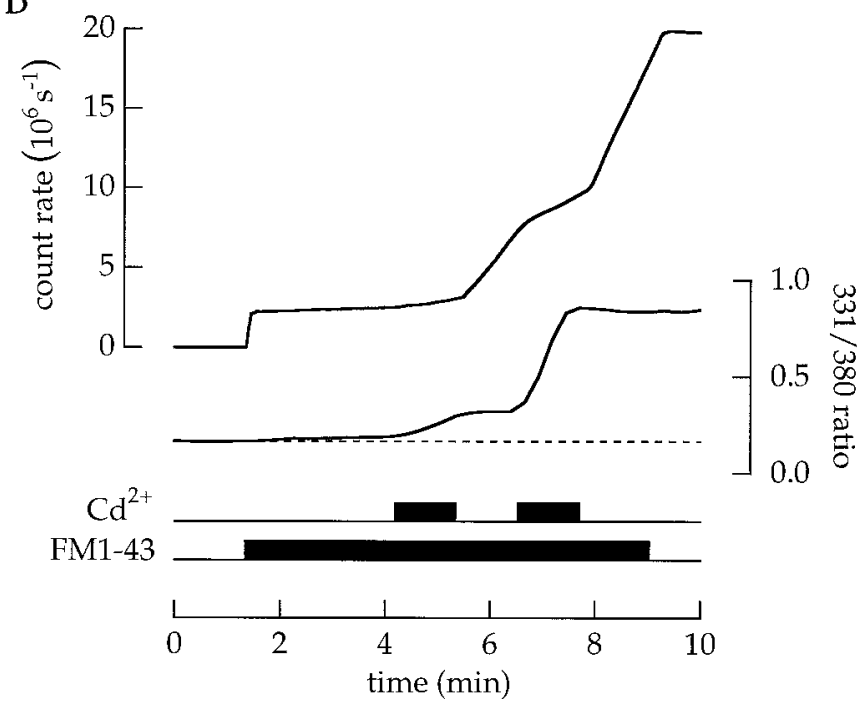

Figure 16. The combination of $\mathrm{Cd}^{2+}$ and FM1-43 increased membrane permeability to both $\mathrm{Cd}^{2+}$ and FM1-43. Cells were loaded with fura-2. $A, \mathrm{Cd}^{2+}$ does not normally enter a terminal. The cell was superfused alternately with an extracellular saline containing $2 \mathrm{mM} \mathrm{Mg}^{2+}$ (no added $\mathrm{Ca}^{2+}$ ) and a saline containing $2 \mathrm{mM} \mathrm{Cd}^{2+}$. There was little change in the ratio of fura- 2 fluorescence produced by 331 and $380 \mathrm{~nm}$ light, indicating that $\mathrm{Cd}^{2+}$ did not enter. $B, \mathrm{Cd}^{2+}$ enters a terminal stained with FM1-43. The cell was superfused with an extracellular saline containing $2 \mathrm{~mm}$ $\mathrm{Mg}^{2+}$ (no added $\mathrm{Ca}^{2+}$ ). FM1-43 $(20 \mu \mathrm{M})$ was added to the saline. When $\mathrm{Mg}^{2+}$ was replaced by $\mathrm{Cd}^{2+}$, fura-2 fluorescence indicted an increase in intracellular, divalent ions. After returning to the $\mathrm{Mg}^{2+}$-rich saline, the rate of FM1-43 entry increased.

\section{REFERENCES}

Bader CR, Bertrand D, Schwartz EA (1982) Voltage-activated and calcium-activated currents studied in solitary rod inner-segments from the salamander retina. J Physiol (Lond) 331:253-284.

Bers DM, Patton CW, Nuceitelli R (1994) A practical guide to the preparation of $\mathrm{Ca}^{2+}$ buffers. Methods Cell Biol 40:3-29.
Betz WJ, Mao F, Bewick GS (1992) Activity-dependent fluorescent staining and destaining of living vertebrate motor nerve terminals. J Neurosci 12:363-375.

Betz WJ, Mao F, Smith CB (1996) Imaging exocytosis and endocytosis. Curr Opin Neurobiol 6:365-371.

Fasolato C, Zottini M, Clementi E, Zacchetti D, Meldolesi J, Pozzan T (1991) Intracellular $\mathrm{Ca}^{2+}$ pools in PC12 cells. Three intracellular pools are distinguished by their turnover and mechanisms of $\mathrm{Ca}^{2+}$ accumulation, storage, and release. J Biol Chem 266:20159-20167.

Grynkiewicz G, Poenie M, Tsien RY (1985) A new generation of $\mathrm{Ca}^{2+}$ indicators with greatly improved fluorescence properties. J Biol Chem 260:3440-3450.

Heidelberger R, Matthews G (1992) Calcium influx and calcium current in single synaptic terminals of goldfish retinal bipolar neurons. J Physiol (Lond) 447:235-256.

Heidelberger R, Heinemann C, Neher E, Matthews G (1994) Calcium dependence of the rate of exocytosis in a synaptic terminal. Nature 371:513-515.

Jankowski JA, Schroeder TJ, Holz RW, Wightman RM (1992) Quantal secretion of catecholamines measured from individual bovine adrenal medullary cells permeabilized with digitonin. J Biol Chem 267:18329-18335.

Katz B, Miledi R (1967) A study of synaptic transmission in the absence of nerve impulses. J Physiol (Lond) 192:407-436.

Korn H, Faber DS (1991) Quantal analysis and synaptic efficacy in the CNS. Trends Neurosci 14:439-445.

Lagnado L, Gomis A, Job C (1996) Continuous vesicle cycling in the synaptic terminal of retinal bipolar cells. Neuron 17:957-967.

Raviola E, Gilula NB (1975) Intramembrane organization of specialized contacts in the outer plexiform layer of the retina. A freeze-fracture study in monkeys and rabbits. J Cell Biol 65:192-222.

Redman S (1990) Quantal analysis of synaptic potentials in neurons of the central nervous system. Physiol Rev 70:165-198.

Rieke F, Schwartz EA (1996) Asynchronous transmitter release: control of exocytosis and endocytosis at the salamander rod synapse. J Physiol (Lond) 493:1-8.

Ryan TA, Reuter H, Smith SJ (1997) Optical detection of a quantal presynaptic membrane turnover. Nature 388:478-482.

Stryer L (1978) Fluorescence energy transfer as a spectroscopic ruler. Annu Rev Biochem 47:819-846.

Vida TA, Emr SD (1995) A new vital stain for visualizing vacuolar membrane dynamics and endocytosis in yeast. J Cell Biol 128:779-792.

von Gersdorff H, Matthews G (1994a) Dynamics of synaptic vesicle fusion and membrane retrieval in synaptic terminals. Nature 367:735-739.

von Gersdorff H, Matthews G (1994b) Inhibition of endocytosis by elevated internal calcium in a synaptic terminal. Nature 370:652-655.

von Gersdorff H, Vardi E, Matthews G, Sterling P (1996) Evidence that vesicles on the synaptic ribbon of retinal bipolar neurons can be rapidly released. Neuron 16:1221-1227. 